\title{
Thirst in Patients with Heart Failure
}

Description of thirst dimensions and associated factors with thirst

\section{Nana Waldréus}

\author{
Division of Nursing Science \\ Department of Social and Welfare Studies \\ Linköping University, Sweden \\ Linköping 2016
}
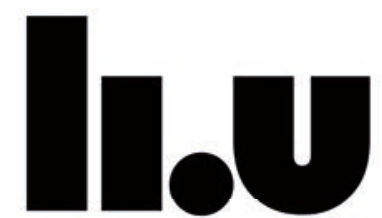

LINKÖPING UNIVERSITY 
Thirst in Patients with Heart Failure- Description of thirst dimensions and associated factors with thirst

CCNana Waldréus, 2016

Cover by: Adam Hagelin

Published article has been reprinted with the permission of the copyright holder.

Printed in Sweden by LiU-Tryck, Linköping, Sweden, 2016

ISBN 978-91-7685-808-0

ISSN 0345-0082 
To my family

Michael, Adam and Alex, Nina and Tuula

"It is the nature of the world of form that nothing stays fixed for very long-and so it starts to fall apart again. Forms dissolve; new forms arise. Watch the clouds. They will teach you about the world of form." 



\section{CONTENTS}

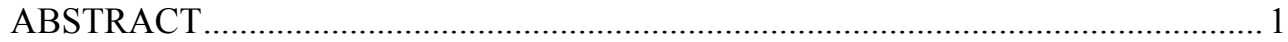

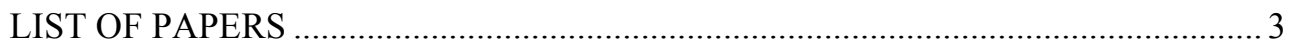

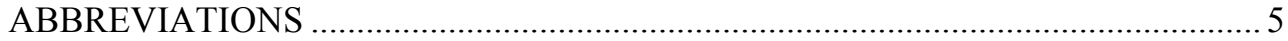

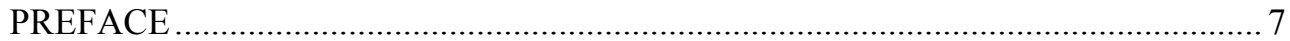

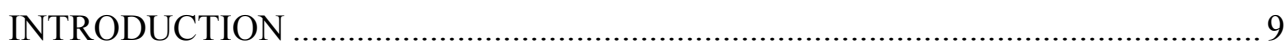

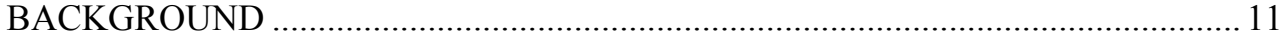

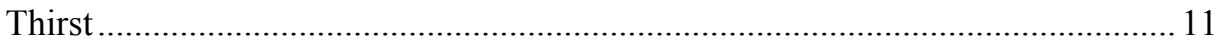

Definition and description of thirst............................................................. 11

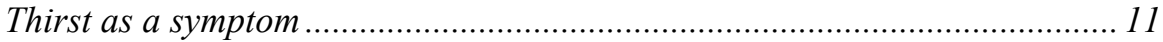

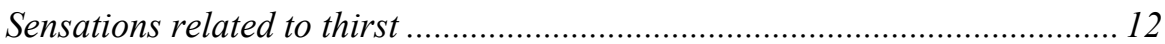

Underlying mechanisms of thirst ................................................................. 12

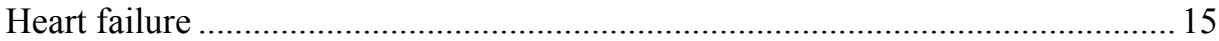

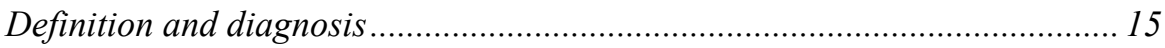

Epidemiology, aetiology, co-morbidities and prognosis ................................ 16

Symptoms and health-related quality of life .................................................. 17

Pharmacological and non-pharmacological treatment.................................. 17

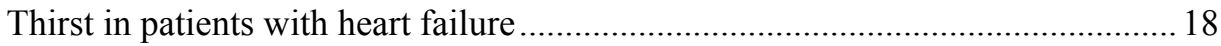

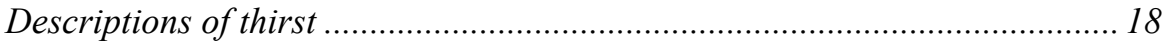

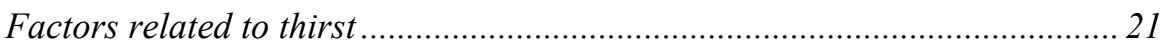

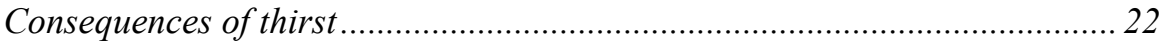

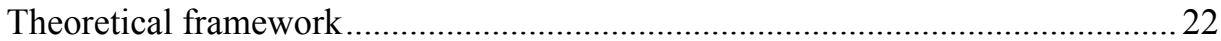

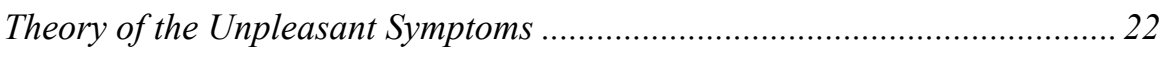

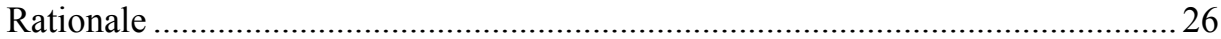

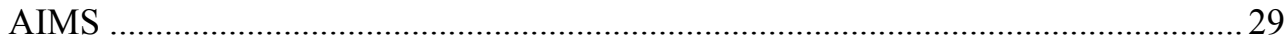

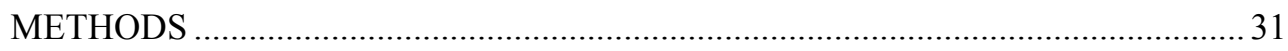

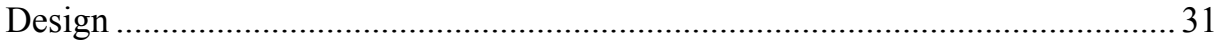

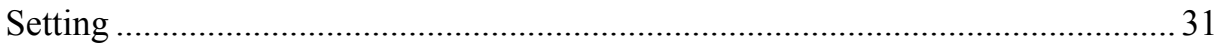




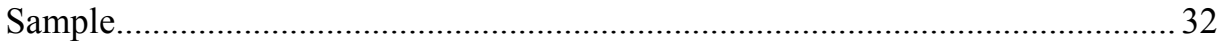

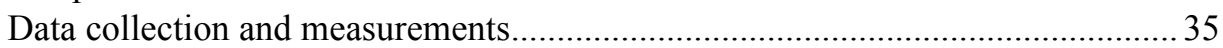

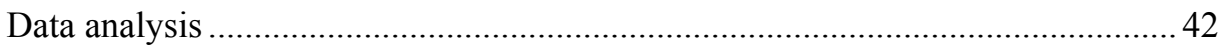

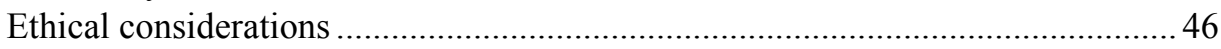

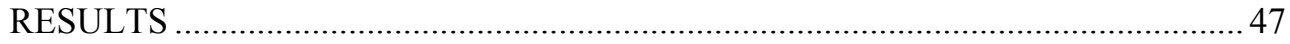

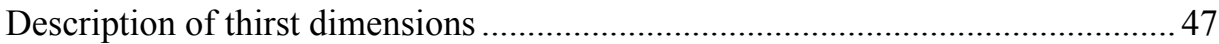

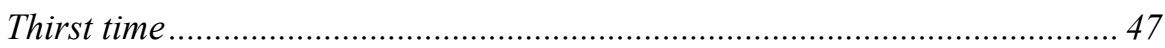

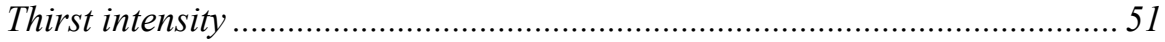

Thirst distress................................................................................... 53

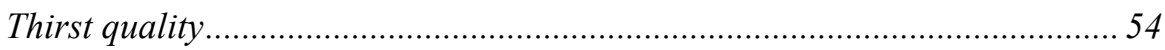

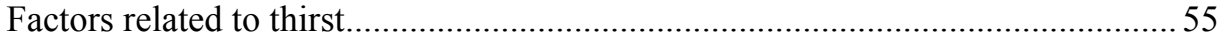

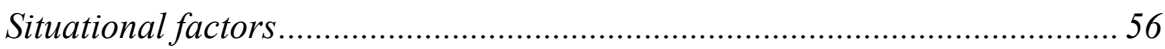

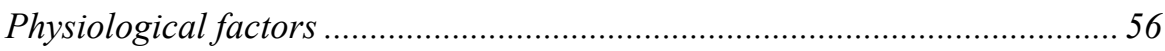

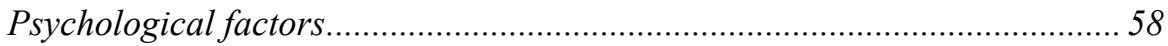

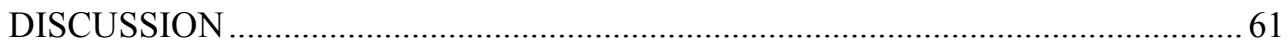

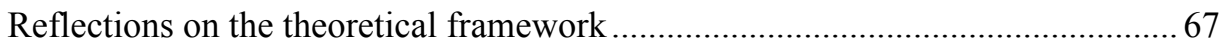

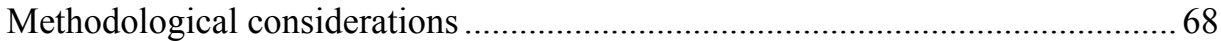

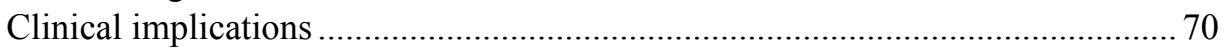

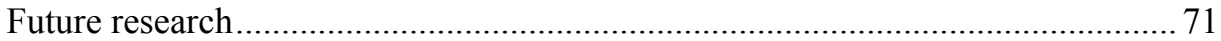

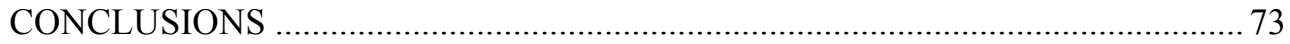

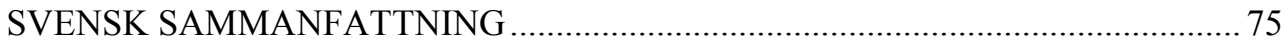

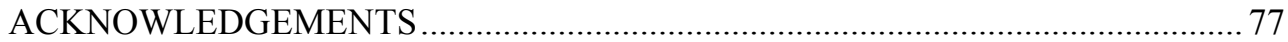






\section{ABSTRACT}

Introduction: Nurses and other health care professionals meet patients with heart failure (HF) who report they are thirsty. Thirst is described by the patients as a concern, and it is distressing. Currently there are no standardized procedures to identify patients with increased thirst or to help a patient to manage troublesome thirst and research in the area of thirst is scarce. In order to prevent and relieve troublesome thirst more knowledge is needed on how thirst is experienced and what factors cause increased thirst.

Aim: The aim of this thesis was to describe the thirst experience of patients with HF and describe the relationship of thirst with physiological, psychological and situational factors. The goal was to contribute to the improvement of the care by identifying needs and possible approaches to prevent and relieve thirst in patients with HF.

Methods: The studies in this thesis used a cross-sectional design (Study I) and prospective observational designs (II-IV). Studies include data from patients with HF who were admitted to the emergency department for deterioration in HF (I, IV) or visited an outpatient HF clinic for worsening of HF symptoms (III); others were patients who were following up after HF hospitalization (II), and patients with no HF diagnosis who sought care at the emergency department for other illness (I). Patients completed questionnaires on thirst intensity, thirst distress, HF self-care behaviour, feeling depressive and feeling anxious. Data on sociodemographic, clinical characteristics, pharmacological treatment and prescribed fluid restriction were retrieved from hospital medical records and by asking the patients. Data were also collected from blood, urine and saliva samples to measure biological markers of dehydration, HF severity and stress.

Results: Thirst was prevalent in 1 out of 5 patients (II) and $63 \%$ of patients with worsening of HF symptoms experienced moderate to severe thirst distress at hospital admission (IV). Patients at an outpatient HF clinic who reported thirst at 
the first visit were more often thirsty at the follow-up visits compared to patients who did not report thirst at the first visit (II). Thirst intensity was significantly higher in patients hospitalized with decompensated HF compared to patients with no HF (median 75 vs. $25 \mathrm{~mm}$, visual analogue scale [VAS] 0-100 mm; $P<$ 0.001) (I). During optimization of pharmacological treatment of HF, thirst intensity increased in $67 \%$ of the patients. Thirst intensity increased significantly more in patients in the high thirst intensity group compared to patients in the low thirst intensity group (median $+18 \mathrm{~mm}$ vs. $-3 \mathrm{~mm} ; P<0.001$ ) (III). Patients who were admitted to the hospital with high thirst distress continued to have high thirst distress over time (IV). A large number of patients were bothered by thirst and feeling dry in the mouth when they were thirsty (III, IV). Patients with a fluid restriction had high thirst distress over time and patients who were feeling depressed had high thirst intensity over time (IV). Thirst was associated with fluid restriction (III), a higher serum urea (II-III), and depressive symptoms (II).

Conclusions: A considerable amount of patients with HF experiences thirst intensity and thirst distress. Patients who reported thirst at the first follow-up more often had thirst at the subsequent follow-ups. The most important factors related to thirst intensity or thirst distress were a fluid restriction, a higher plasma urea, and depressive symptoms. Nurses should ask patients with HF if they are thirsty and measure the thirst intensity and thirst distress, and ask if thirst is bothering them. Each patient should be critically evaluated if a fluid restriction really is needed, if the patient might be dehydrated or needs to be treated for depression.

Keywords: heart failure, thirst, fluid restriction, thirst intensity, thirst distress, thirst frequency, thirst quality, trajectory, dehydration, fluid restriction, depression. 


\section{LIST OF PAPERS}

This thesis is based on the following papers, which will be referred to in the text by their Roman numerals.

I. Waldréus N, Sjöstrand F, Hahn RG. Thirst in the elderly with and without heart failure. Archives of Gerontology and Geriatrics 2011; 53: 174-178.

II. Waldréus N, van der Wal M, Hahn RG, van Veldhuisen DJ, Jaarsma T. Thirst trajectory and factors associated with persistent thirst in patients with heart failure. Journal of Cardiac Failure 2014; 20: 689-695.

III. Waldréus N, Hahn RG, Lyngå P, van der Wal M, Hägglund E, Jaarsma T. Changes in thirst intensity during optimization of heart failure medical therapy by nurses at the outpatient clinic. The Journal of Cardiovascular Nursing, 2015; DOI: 10.1097/JCN.0000000000000319.

IV. Waldréus N, Chung M, van der Wal MHL, Jaarsma T. Thirst trajectories in patients with heart failure: a linear mixed analysis of contributors to thirst. Submitted.

Published articles have been reprinted with the permission of the copyright holders. 


\section{ABBREVIATIONS}

$\mathrm{COACH}$

HF

LVEF

NT-proBNP

NYHA

RAAS

VAS
Coordinating study evaluation Outcomes of Advising and Counselling in Heart failure

Heart Failure

Left Ventricular Ejection Fraction

N-terminal of the prohormone Brain Natriuretic Peptide

New York Heart Association

Renin-Angiotensin-Aldosterone System

Visual Analogue Scale 


\section{PREFACE}

During the years that I worked as a nurse in advanced palliative home care, I took care of patients with severe heart failure. The patients I met had several very distressing symptoms. Some of the symptoms were typical for the heart failure condition, such as dyspnoea and fatigue. In order to relieve these symptoms, they received treatment with high doses of diuretics. In addition to the diuretic treatment, patients were advised to limit their fluid intake. The restriction of fluids was based on logical reasoning and was believed to make it easier for the heart to pump blood if less water were in the bloodstream. I always remember that the patients often complained about being thirsty.

Since the main goal in palliative care was symptom relief, it was very difficult for me to see these patients suffer from thirst and not being able to help them in a proper way. I also often faced the challenge to help the patients to find ways how to best follow their fluid restriction, although I knew that they suffered from thirst, and they really would have had to drink to get relief. I searched in literature to find any advice on thirst in patients with heart failure. The only information I found was in a book on physiology and disease, in which it was described that patients with heart failure could have increased thirst. I could not find evidence based effective interventions that might help patient to relieve their thirst or cope with it.

The only relief I could offer the patients was to moisten their mouth with a small amount of water and have them suck on ice cubes. Several years later, I got the opportunity to work with research. When looking for a project to complete my specialist education about the care of patients with heart failure, I remembered the patients who were suffering with thirst, and I performed my first study with patients with heart failure and thirst. This was the beginning of my thesis. 


\section{INTRODUCTION}

Thirst is a sensation that causes a powerful behavioural drive to drink water. ${ }^{1}$ The thirst sensation can be so strong that the craving to drink water cannot be ignored. ${ }^{1,2}$ The function of thirst is to drink to maintain body water balance and survival. ${ }^{3}$ In daily practice, nurses and other health-care professionals meet patients with heart failure (HF) with increased and persistent thirst at hospitals and outpatient clinics. ${ }^{4,5}$ Patients' $^{\prime}$ with HF describes thirst as a concern when they have a fluid restriction. 6,7 Thirst is also described to be distressing in patients with HF. ${ }^{8,9}$ Thirst can negatively affect quality of life and therefore be an essential part of the patient's suffering., $4,8,10,11$

Patients who have HF suffer from an irreversible and progressive condition with periods of deterioration of $\mathrm{HF}$ and hospitalization. ${ }^{12} \mathrm{HF}$ is reported to be the leading cause of hospitalizations in patients aged 65 years and shortens the life expectancy. ${ }^{13,14}$ With such disease progression, issues about prevention and relief of suffering from thirst becomes especially important. The role of nursing is to provide individualised care and help patients to manage troublesome symptoms and to increase health and well-being. ${ }^{15-19}$ However, standard procedures for identification or risk assessment of thirst in both hospital and outpatient clinics are missing.

Although troublesome thirst in patients with HF has been recognized since the early 1900 's, ${ }^{5}$ studies of thirst in this patient group have not been conducted until recently. However, the current scientific knowledge about thirst in patients with HF is still weak. ${ }^{11,20}$ There are some studies about thirst in patients with HF, most of them examining effects of restricting fluid intake. ${ }^{11,20}$ Thirst was a secondary outcome in all of the studies or a statement regarding thirst given by the HF patients in interviews. ${ }^{11}$ No studies were conducted to describe thirst experience more thoroughly or to find factors that might increase thirst in patients with HF. It is also important to display changes in thirst over time, considering that 
other symptoms can change over time and that knowledge about influencing factors can be targeted for interventions. ${ }^{21-23}$

There are several issues that need to be studied in order to increase knowledge about thirst in patients with HF. There is no research regarding the prevalence of thirst in patients with HF and the information about thirst distress is limited. There are studies with results about thirst intensity, but only in relation to fluid restriction interventions. Some statements have been made about thirst in interview studies, but we need more knowledge about how patients experience thirst. This information would give more knowledge about how thirst affects patients with HF. Furthermore, knowledge about factors that are associated with increased thirst in patients with HF is missing. By identifying factors that promote thirst would help when planning for an intervention to relieve thirst. Moreover, the prognostic significance of thirst is unknown. Gaining more knowledge about thirst, as experienced by the patients, and factors that promote thirst, would be valuable and be used to design an intervention to prevent and relive thirst in patients with $\mathrm{HF}^{24}$ 


\section{BACKGROUND}

\section{Thirst}

\section{Definition and description of thirst}

Thirst has been defined as a sensation and a symptom that is associated with a craving to drink. ${ }^{2}$ Others define thirst also as a sensation with dryness in the mouth and throat, which is associated with a desire for liquids ${ }^{25}$ or as a deepseated sensation or desire for water and this sensation cannot be ignored because it causes a powerful behavioural drive to drink water. ${ }^{1}$ For patients with renal failure, thirst was previously defined as a "conscious and subjective sensation of desiring fluids", 26 (p. ${ }^{338)}$ however there is no uniform definition of thirst. The various definitions suggest that thirst is subjective, with a feeling of dryness in the mouth, and associated with a desire or craving for water. Therefore, for this thesis the definition of thirst is a sensation associated with dryness in the mouth and a desire or craving for water to drink.

Thirst has previously been measured and described in healthy persons, ${ }^{27}$ in patients with renal failure, ${ }^{28-30}$ terminal illness, ${ }^{31,32}$ diabetes, ${ }^{33,34}$ in critically ill patients at intensive care unit, ${ }^{35,36}$ and in patients with HF. ${ }^{11,20}$ Thirst has mostly been described in research with the sensation of intensity, ${ }^{11,26,28,35,37-41}$ which refers to the strength of the thirst. ${ }^{37}$ Thirst has also been described using the measurement of distress, ${ }^{8,9,26,35}$ which is to what degree the patient is bothered by thirst. ${ }^{37}$ Thirst can also be described as the frequency of thirst ${ }^{35,37,42}$ and as the quality of thirst, 6, 7, 10,36 which is how thirst is described to feel like and its associated discomfort. $^{37}$

\section{Thirst as a symptom}

A symptom is defined as a "perceived indicator of change in normal functioning as experienced by the patient". ${ }^{43}$ (p. 3) Since the $14^{\text {th }}$ century, the term "symptom" 
has been used to refer to an individual's manifestations of illness. ${ }^{44}$ Illness is described as a decline of well-being manifested as symptoms. ${ }^{45}$ A symptom indicates a change in normal body function or feeling. ${ }^{43}$ It can be described as observable only by the person and can not be objectively measured. Therefore, it is known only by the report of the person experiencing it. ${ }^{17} \mathrm{~A}$ sign, on the other hand, is an alteration that can be detected by others and measured objectively e.g. by biomedical disease markers. ${ }^{44}, 46$ The definitions used for thirst describe thirst as a symptom. 1, 2, 25, 26, 43 Thirst can only be known by the person experiencing it and is not detectable by others. Thirst is an indicator of change in normal functioning and can reflect changes in the physiological functioning. ${ }^{47}$

\section{Sensations related to thirst}

There are some closely related sensations to thirst that need to be clarified. When being thirsty, one can sometimes, at the same time be hungry. ${ }^{48}$ But hunger is a different sensation, with other physiological mechanisms. Hunger is the sensation that promotes accomplishment of minimal energy needs. ${ }^{3,49}$ Not eating anything, but still drinking, is not fatal for many weeks. ${ }^{48}$ In contrast, not to be able to quench thirst by drinking leads not only to intense thirst, but also to reduced function within days and death within a week. ${ }^{48}$ Sometimes appetite is used as a synonym for thirst. However, the distinction is that appetite is the sensation described as a desire for food or to eat food due to hunger. ${ }^{3}$ Appetite is regulated by interaction between the digestive tract, adipose tissue and the brain. Dry mouth is also often associated with thirst and sometimes even described synonymously with thirst. ${ }^{25}$ Dry mouth is the sensation of feeling dry in mouth. ${ }^{3}$

\section{Underlying mechanisms of thirst}

Although it is not totally clear, several causes for thirst are described, such as changes in body fluids, an increased sympathetic activity and pharmacological treatment. ${ }^{3,50-52}$ 


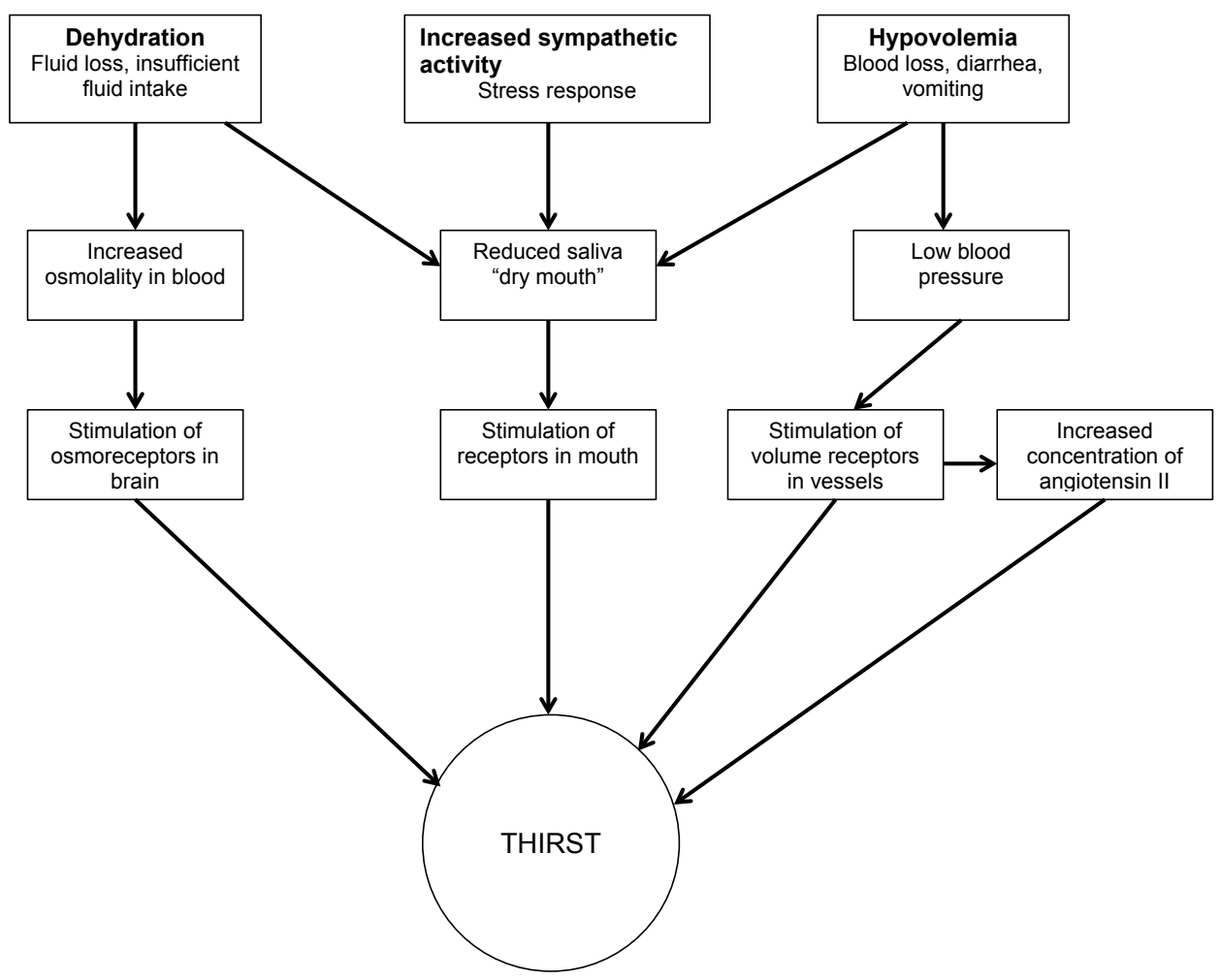

Figure 1. Physiological factors influencing thirst. ${ }^{3,47,50,52-55}$

\section{Changes in body fluids}

Thirst acts as a regulator of body hydration and water intake. ${ }^{3}$ In healthy persons, thirst is mainly triggered by the thirst centre in the brain in response to changes in body fluids caused by dehydration and hypovolemia (Figure 1). ${ }^{3}$ The increase of osmolality in blood due to dehydration is the most common stimuli for thirst (Figure 1). ${ }^{3,47}$ Hypovolemia causes low blood pressure, which stimulates volume receptors and activates the renin-angiotensin-aldosterone system (RAAS). ${ }^{3}$ Kidneys release the enzyme renin, which stimulates the production of the hormone angiotensin II. ${ }^{47,56}$ Angiotensin II promotes the release of aldosterone, which re- 
tains sodium and preserves water. Angiotensin II has been associated with thirst in animals and patients with renal failure. ${ }^{3,28,55}$ In elderly persons, thirst can be impaired due to attenuated sensitivity of receptors responding to changes in blood volume or reduced cerebral blood flow. ${ }^{57-59}$ Dehydration and hypovolemia can have an influence on the salivary flow in the mouth and be associated with dry mouth (Figure 1, page 13).3,50,52

An increase of the body fluids stretches the walls of the heart and release natriuretic peptides, such as the $\mathrm{N}$-terminal of the prohormone brain natriuretic peptide (NT-proBNP). ${ }^{3}$ NT-proBNP affects the kidneys to increase the excretion of salt and water. In addition, serum urea is suggested to be a marker to patient body fluid status as well as to neurohormonal activation. ${ }^{60-62}$ Sodium intake or eating salty foods can also induce thirst in healthy persons. ${ }^{63}$, 64 Several conditions that alter or disturb the body fluid balance may potentially cause increased thirst, such as vomiting, ${ }^{3}$ bleeding,${ }^{3}$ terminal illness, ${ }^{31,32}$ diabetes, ${ }^{33,}{ }^{34}$ renal failure, ${ }^{28,41}$ and heart failure. ${ }^{11,20}$

\section{Sympathetic activity}

The sympathetic stress response causes vasoconstriction of salivary glands and decreases salivary secretion, which can be experienced as a dry mouth (Figure 1, page 13$){ }^{3}$ Dry mouth can be sensed by specific receptors detecting osmotic changes or friction in the mucosa, and detected by the thirst centre in the brain. ${ }^{53}$ Receptors in the mouth can also sense changes of cold and signals the thirst centre in the brain (Figure 1, page 13). ${ }^{54}$ Gargling with cold water for 2 minutes or sucking on an ice-cube can alleviate thirst, but only for 15 minutes. ${ }^{65}$ This effect is explained by the oropharyngeal stimuli of sensory receptors in the mouth and throat. $^{53}$

\section{Pharmacological treatment}

Anticholinergic treatment (e.g. omeprazole and atropine) and central-acting psychoactive agents (e.g. antidepressants, antihistamines and benzodiazepines) are the most common medications causing hyposalivation and thirst. ${ }^{51}$ Other phar- 
macological treatments, such as opioids, beta blockers and diuretics are also associated with thirst..$^{20,50,51,66}$

\section{Heart failure}

\section{Definition and diagnosis}

$\mathrm{HF}$ is an irreversible and progressive condition with typical symptoms and signs resulting from an abnormality of cardiac structure. ${ }^{12}$ The abnormalities in HF lead to a failure to pump enough blood to deliver sufficient levels of oxygen to body tissues. The diagnosis of HF with reduced left ventricular ejection fraction (LVEF) therefore requires typical symptoms of HF, specific signs of HF and reduced LVEF ( $\leq 50 \%$ ) to be satisfied. ${ }^{12}$ The neurohormonal systems RAAS and sympathetic nervous system are highly activated in HF and are associated with the development of the symptoms. ${ }^{12}$ Typical symptoms in HF are dyspnoea, ankle swelling and fatigue, and specific signs of HF are elevated jugular venous pressure, third heart sound and cardiac murmur. ${ }^{12}$ The concentration of the Nterminal of the prohormone brain natriuretic peptide (NT-proBNP) is used to diagnose HF, optimize medication and used to evaluate the effects of HF treatment. ${ }^{12}$ An exclusion NT-proBNP cut-off point for acute onset of HF or worsening of HF symptoms is $300 \mathrm{pg} / \mathrm{ml}$, and for gradual onset of symptoms the cut-off point is $100 \mathrm{pg} / \mathrm{ml}$. Stable HF is defined as a treated patient with symptoms and signs of HF, which remain unchanged for at least a month. ${ }^{12}$ Stable HF can deteriorate, and the patient is then described as decompensated or unstable. The most commonly used nomenclature, which classifies the degree of HF severity has been developed by the New York Heart Association (Figure 2). An increase in the NYHA class describes an increase in symptom severity. ${ }^{67}$ 


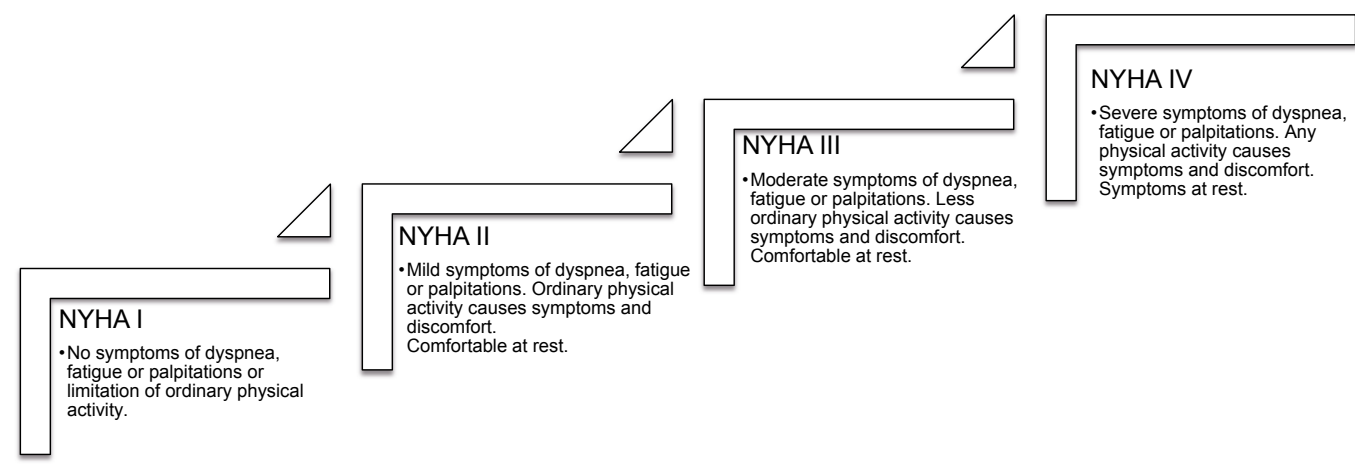

Figure 2. New York Heart Association classification of the degree of symptom severity of heart failure. ${ }^{67}$

\section{Epidemiology, aetiology, co-morbidities and prognosis}

About 26 million people worldwide have HF, ${ }^{68}$ and in Sweden the estimated prevalence for HF is $2.2 \%$ for both men and women. ${ }^{69}$ The prevalence increases with age, being $7 \%$ to $30 \%$ in patients aged 70 years and older. In Sweden the mean age of the patients with HF was $77 \pm 13$ years (year 2010) and $90 \%$ of them were 60 years or older. ${ }^{69}$ Women are older than men at the HF onset (mean age 76 vs. 70 years). The most common causes of HF are related to coronary artery disease, such as angina pectoris or myocardial infarction and non-ischemic diseases as hypertension, arrhythmias and valve diseases. ${ }^{12}$ Co-morbidities, such as obstructive pulmonary disease, anaemia, diabetes, and renal failure are common in HF, and associated with poor prognosis. ${ }^{12}$ The estimated five-year mortality is between $48-65 \%$ in patients with HF after the initial diagnosis. ${ }^{70}$ In Sweden, the estimated one-year mortality is $24 \%$ in patients with NYHA class III and $50 \%$ in patients with class IV. ${ }^{14}$ 


\section{Symptoms and health-related quality of life}

In addition to the previously reported HF symptoms patients can also experience other symptoms, such as dry mouth, dizziness, pain, sweats, nausea, and thirst. ${ }^{11,}$ ${ }^{71-74}$ It has also been found that depression, which can be prevalent in between $30 \%$ and $70 \%$ of the patients with HF, is associated with more symptoms and symptom distress ${ }^{72,73,75}$ Symptoms are stated to be hallmarks of HF severity, but can also be an essential part of the patient's distress in periods of stable HF condition. $^{45,76}$ A trajectory, or in other words, the course of a symptom reflects changes in the symptom experience and identify important factors that are related to the symptom. ${ }^{21,23}$ Symptoms in patients with HF can disappear spontaneously or return, but if they continue over time they can cause a feeling of distress and trigger hospitalization..$^{21-23}$ Health-related quality of life is described as being poor in patients with $\mathrm{HF}^{77,78}$ Greater number of symptoms in patients with $\mathrm{HF}$ has been found to be associated with the decrease in quality of life. ${ }^{73}$ Symptoms have an impact on their daily lives and are associated with low health-related quality of life. ${ }^{12,73,77,79}$

\section{Pharmacological and non-pharmacological treatment}

Pharmacological treatments for patients with reduced ejection fraction are recommended to consist of an angiotensin converting enzyme (ACE) (or angiotensin receptor blocker, ARB), a beta-blocker and a mineralcorticoid receptor antagonist (MRA). ${ }^{12}$ The basis for the pharmacological treatment of HF is to interrupt neurohumoral processes. A new promising drug, an angiotensin-neprilysin inhibitor, showed a better early and sustained reduction in NT-proBNP, and reduced worsening of HF symptoms, as well as HF hospitalization compared with an ACE ${ }^{80}$ Diuretics are used to give relieve of symptoms and signs of congestion. Good pharmacological HF treatment can reduce hospitalizations and improve health-related quality of life and survival. ${ }^{12}$

The non-pharmacological treatment is an important part of the treatment in patients with HF. Device therapy, such as pacemakers and implantable cardio- 
verter defibrillators, can improve the function of the heart, exercise capacity and symptoms. ${ }^{12,81}$ Self-care management is part of successful HF treatment and can significantly impact on symptoms, functional capacity, well-being, morbidity, and prognosis. ${ }^{76,82} \mathrm{HF}$ specific self-care behaviours include activities such as taking medication as prescribed, eating a low-sodium diet, weighing every day, exercising regularly, and limiting fluid intake. ${ }^{76}$ According to guidelines and practical recommendations, patients with HF should avoid excessive fluid intake. ${ }^{12,76}$ A fluid restriction of 1.5-2.0 L/day may be considered in patients with severe HF to relieve symptoms and congestion.

Self-care involves also symptom recognition, as well as the evaluation, monitoring and management of a symptom, and to contact nurse/doctor if $\mathrm{HF}$ symptoms get worse. ${ }^{18,76}$ For patients, there can be obstacles to perform self-care, such as having troublesome thirst when they are restricting their fluid intake. ${ }^{10}$ Thirst makes the fluid restriction even more difficult to follow. ${ }^{10,11}$ Patients may feel guilt when they are not adhering to the recommendation and thinking about breaking the rules. ${ }^{10}$ Patients success in their self-care depends on motivation, skills, habits, and support from others. ${ }^{18}$ There is a need to help patients with HF to recognize, interpret and monitor symptoms and to use appropriate self-care management strategies for symptoms, as well as to support the patients. ${ }^{83}$

\section{Thirst in patients with heart failure}

\section{Descriptions of thirst}

The number of studies reporting about thirst in patients with HF has increased during the last decade (Table 1). Seven out of thirteen studies were randomized trials examining the effects of a fluid restriction. ${ }^{8,38,39,84-87}$ Three studies used qualitative methods to describe how it is to live with HF and to explore reasons and motivations for compliance with HF treatment. ${ }^{6,7,10}$ A randomized controlled trial investigated effects of a drug for HF. ${ }^{42}$ Finally, one study described symptoms in patients with HF at the end of life, ${ }^{4}$ and another examined the rela- 
tionship between thirst distress and quality of life (Table 1). ${ }^{9}$ The studies included patients in all NYHA classes, and the mean age ranged from 44 to 86 years. The mean ejection fraction was $23 \%$ to $45 \%$.

Table 1. An overview of studies on thirst in patients with heart failure (continues on the next page).

\begin{tabular}{|c|c|c|c|c|}
\hline $\begin{array}{l}\text { Year (ref) } \\
\text { and design }\end{array}$ & Purpose & Patients & $\begin{array}{l}\text { Thirst } \\
\text { dimension } \\
\text { measurement }\end{array}$ & Thirst outcomes \\
\hline
\end{tabular}

$\begin{array}{llll}2015^{8} & \text { Test an educational and } & \text { N=25; } & \text { Distress } \\ \text { Randomized } & \text { behavioural intervention } & \text { Stable HF; } & \text { 6-item Thirst } \\ \text { clinical trial } & \begin{array}{l}\text { on adherence with pre- } \\ \text { scribed fluid restriction }\end{array} & \text { EF 23\%; } & \text { NYHA II-IV; } \\ & \begin{array}{l}\text { and outcome measures scale } \\ \text { (score 6-30) }\end{array} & \text { Age 44-83 years } & \end{array}$

The IG increased thirst distress between 3 to 6 months $(\mathrm{P}<0.01)$. IG: At baseline mean (SD) thirst distress score was $16 \pm 7$, at 3 month $15 \pm 6$ and at 6 -month $18 \pm 5$ CG: Baseline 15 \pm 8 , 3-month $13 \pm 8$ and at 6 -month $14 \pm 8$

\begin{tabular}{|c|c|c|}
\hline $\begin{array}{l}2013^{86} \\
\text { Randomized } \\
\text { clinical trial }\end{array}$ & $\begin{array}{l}\text { Evaluate the effect of } \\
\text { fluid and salt restriction } \\
\text { on NYHA class, hospi- } \\
\text { talization, body weight, } \\
\text { oedema, quality of life, }\end{array}$ & $\begin{array}{l}\text { N=97; } \\
\text { Stable HF; } \\
\text { EF 34\%/37\%; } \\
\text { NYHA II-III; } \\
\text { Age } 75 \text { years }\end{array}$ \\
\hline
\end{tabular}

\begin{tabular}{|c|c|c|c|}
\hline $\begin{array}{l}2013^{38} \\
\text { Randomized } \\
\text { controlled } \\
\text { trial }\end{array}$ & $\begin{array}{l}\text { Examine outcomes after } \\
\text { implementing a } 1000 \\
\text { ml/day fluid restriction at } \\
30 \text { and } 60 \text { days after } \\
\text { discharge }\end{array}$ & $\begin{array}{l}\text { N=46; Hypo- } \\
\text { natraemic HF; } \\
\text { EF } 23 \pm 12 \% ; \\
\text { NYHA III-IV; } \\
\text { Age } 63 \text { years }\end{array}$ & $\begin{array}{l}\text { Intensity } \\
\text { VAS 0-100 } \\
\text { mm }\end{array}$ \\
\hline
\end{tabular}

\begin{tabular}{|c|c|c|c|}
\hline $\begin{array}{l}2013^{39} \\
\text { Randomized } \\
\text { clinical trial }\end{array}$ & $\begin{array}{l}\text { Compare the effects of a } \\
\text { fluid- and sodium re- } \\
\text { stricted diet vs. diet with } \\
\text { no such restriction on } \\
\text { weight loss and clinical } \\
\text { stability }\end{array}$ & $\begin{array}{l}\text { N=75; Acute } \\
\text { decompensated } \\
\text { HF; } \\
\text { EF } 26 \% ; \\
\text { NYHA III-IV; } \\
\text { Age } 60 \text { years }\end{array}$ & $\begin{array}{l}\text { Intensity } \\
\text { NRS 0-10 }\end{array}$ \\
\hline $\begin{array}{l}2010^{87} \\
\text { Randomized } \\
\text { clinical trial }\end{array}$ & $\begin{array}{l}\text { Study effects of fluid and } \\
\text { sodium intake in HF } \\
\text { patients on quality of } \\
\text { life, physical capacity } \\
\text { and thirst }\end{array}$ & $\begin{array}{l}\text { N=30; } \\
\text { Stable HF; } \\
\text { EF 34\%; } \\
\text { NYHA II-III; } \\
\text { Age } 74 \text { years }\end{array}$ & $\begin{array}{l}\text { Intensity } \\
\text { NRS 0-10 }\end{array}$ \\
\hline
\end{tabular}

There was no difference in thirst intensity between the IG and CG after 12 weeks.

IG: At baseline 4.2 and at 12weeks 4.4 CG: At baseline 4.4 and at 12weeks 5.2

There was no difference between groups in thirst intensity at 30 and 60-days after discharge. IG: median (IQR) thirst intensity was at 30-days 50 (36-66) and at 60-days 40 (20-51) CG: at 30-days 50 (32-65) and at 60-days 50 (13-74)

Thirst intensity (mean, SD) change:

IG: From $4.1 \pm 2.6$ to $5.1 \pm 2.9$ CG: From $3.9 \pm 2.5$ to $3.4 \pm 2.0$. Thirst was significantly higher in the restricted group at study end

There was no difference in thirst intensity between the IG and CG after 12 weeks

IG: At baseline 5.4 and at 12weeks 4.6

CG: At baseline 5.0 and at 12weeks 4.8

HF, heart failure; IG, intervention group; CG, control group; VAS, visual analogue scale; NRS, numerical rating scale. 
Table 1. Continued

\begin{tabular}{llll}
\hline $\begin{array}{l}\text { Year (ref) and } \\
\text { design }\end{array}$ & Purpose & Patients & $\begin{array}{l}\text { Thirst dimen- } \\
\text { sion, measure- } \\
\text { ment }\end{array}$
\end{tabular}

$\begin{array}{llll}2010^{9} & \text { Identify relationships } & \text { N=25; } & \text { Distress } \\ \text { Descriptive } & \text { between fluid intake, } & \text { Stable HF; } & \text { 6-item Thirst } \\ & \text { thirst and quality of life } & \text { EF 23\%; } & \text { distress scale } \\ & \text { in HF } & \text { NYHA II-IV; } & \text { (score 6-30) } \\ & & \text { Age 44-83 years } & \end{array}$

\section{$2010^{10}$ \\ Qualitative descriptive study}

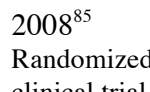

clinical trial

$2008^{84}$
Randomized
clinical trial

$2007^{42}$

Randomized clinical trial

\section{$2007^{7}$}

Qualitative study, phenomenogr. approach

\section{$2006^{6}$}

Qualitative study, phenomenol.hermeneutic method

Explore reasons and
motivations for compli-
ance with HF regimen
and how patients manage
these recommendations

$\mathrm{N}=15$;

Stable HF;

EF 39\%;

NYHA II-IV;

Age 70 years

Compare restrictive and liberal fluid prescription on quality of life, physical capacity, thirst and hospital admission

Study fluid intake on body weight, HF symptoms, quality of life, physical capacity and thirst

Investigate the effects of tolvaptan in patients hospitalized with $\mathrm{HF}$

Describe how persons with HF perceive their daily life

Illuminate meaning of living with severe HF

$\mathrm{N}=4$;

Severe HF

Quality

Interview

$\mathrm{N}=65$;

Stable HF;

$\mathrm{EF}<45 \%$;

NYHA I-IV;

Age 70 years

$\mathrm{N}=63$;

Stable HF;

$\mathrm{EF}<45 \%$;

NYHA I-IV;

Age 69 years

$\mathrm{N}=4133$; HF;

Frequency

EF 40\%;

NYHA III-IV;

Age 69 years

$\mathrm{N}=17$;

Stable HF;

NYHA III-IV;

Age 72 years

Intensity

VAS 0-100 mm

Question,

yes/no

Quality

Interview

NYHA III-IV;

Age 72-81 years

Quality

Interview

Intensity

VAS 0-100 mm

Thirst intensity was scored 51

mm with fluid restriction and 23

$\mathrm{mm}$ with liberal fluid intake

$(\mathrm{P}<0.001)$.

Thirst intensity decreased by $6 \%$ having a fluid restriction and $-24 \%$ with liberal fluid intake $(\mathrm{P}<0.05)$.

Thirst was reported as an adverse event $16 \%$ of the patients with tolvaptan compared with $2 \%$ with placebo $(\mathrm{P}<0.001)$.

Patients described that thirst was enormously annoying and they associated thirst with fluid restriction.

Patients were suffering and struggling from thirst. They felt an irresistible need to drink, but nothing could help to slake their thirst. Thirst was related with fluid restriction and loss of body water when taking diuretics.

$\mathrm{N}=80$; End- $\quad$ Frequency stage HF; Age 86 years
Documentation medical record
Persistent thirst was observed documented in $9 \%$ of the patients' medical record.

HF, heart failure; VAS, visual analogue scale; NRS, numerical rating scale 
Thirst in patients with HF has been reported in the studies by describing the thirst intensity, thirst distress, thirst quality and the frequency of thirst (Table 1). ${ }^{11}$ In most of the studies, thirst has been described using the intensity of the thirst, which was measured with a visual analogue scale (VAS) ranging from 0 (no thirst) to 100 (worst possible thirst) or a numeric rating scale (NRS) from 0 to 10 (Table 1). ${ }^{11,20,39,40,84,86,87}$ Thirst distress in patients with HF has been described in two studies ${ }^{8,9}$ using the Thirst Distress Scale (scores 6-30) developed for patients with renal failure. ${ }^{8,9,26}$ Moderate to severe thirst distress was found in $47 \%$ of patients with HF (Table 1 ). ${ }^{9}$

Qualitative studies have captured thirst in interviews about how it is to live with HF. ${ }^{6,7,10}$ Thirst has been expressed in the patient's own words to be a concern and perceived as very annoying. ${ }^{7}$ Patients with severe HF experienced an irresistible need to drink and described thirst as a struggle in their daily life (Table 1). ${ }^{6}$ Relief of their thirst was only felt for a short time. For some patients, the only way to cope with thirst was to break the rules of the fluid restriction. ${ }^{6}$

\section{Factors related to thirst}

There are a few factors that have been described to influence thirst in patients with $\mathrm{HF}$, such as medication and fluid intake. In a randomized controlled trial with 4133 patients with HF, thirst was found to be related to treatment with the use of drug tolvaptan. ${ }^{42}$ Furthermore, in an interview study patients described that they perceived the loss of body water as a result of using diuretics to be the cause to thirst. ${ }^{6}$ Also, the use of fluid restriction has been stated to be associated with thirst. ${ }^{6,7,10}$ Intervention studies have shown that thirst intensity and thirst distress are increased in patients having a fluid restriction and decreased with a liberal fluid intake. ${ }^{8,39,84,85}$ However, other studies have shown that there is no difference in thirst between patients having fluid restriction and those with a liberal fluid intake. ${ }^{38,86,87}$ Finally, dehydration and the increased neurohormonal activation in HF may play an important role in causing thirst. ${ }^{20}$ 


\section{Consequences of thirst}

A consequence of thirst for patients with HF is that the non-pharmacological treatment advice of a fluid restriction is difficult to follow. ${ }^{6,10,84}$ Fluid restriction can be difficult for some patients, and they might struggle to decide between following the restriction of the fluid intake or their own desire for drinking more water than allowed. ${ }^{6}$ It might become a struggle for the patients to try to control thirst and then blaming themselves when not succeeding in following fluid restriction and gaining in weight. ${ }^{6}$ A lot of time can be spent on thinking about thirst and to being thirsty. Some patients are described to be preoccupied with thirst. ${ }^{10}$ Thirst has been described to have an adverse effect on quality of life. ${ }^{8,9}$, 11

\section{Theoretical framework}

\section{Theory of the Unpleasant Symptoms}

The Theory of Unpleasant Symptoms is used in this thesis to guide the choice of variables of interest to explore the thirst experience in patients with HF, and to explain factors that may affect the thirst experience. ${ }^{88-90}$ The theory can also be used to explore the symptom experience on cognitive or functional performance. ${ }^{43}$ Out of two existing symptom theories, the Theory of Unpleasant Symptoms is less comprehensive and more easy to visualize than the Theory of Symptom Management. ${ }^{91}$ The purpose of the Theory of Unpleasant Symptoms is to improve understanding of symptom experience and to provide information for designing an intervention in order to prevent, improve or manage unpleasant symptoms. $^{37,43}$

The assumption for the Theory of Unpleasant Symptoms is that there are sufficient commonalities between symptoms to warrant a theory that is not limited to one symptom. ${ }^{43}$ The commonalities are that the symptom is defined to be a subjective sensation, can be present as acute or chronic, can occur under normal as well as abnormal or illness conditions, and can result from or be aggravated by 
excessive anxiety or depression. ${ }^{92}$ The Theory of Unpleasant Symptoms has been used in studies as the framework to explore fatigue in patients with myocardial infarction, ${ }^{88}$ to explain the multidimensional characteristics of fatigue in persons with chronic lung disease, ${ }^{89}$ and to explore the influence of dyspnoea duration, distress and intensity on decisions of patients with HF to come to an emergency department. $^{90}$

\section{The components of the Theory of the Unpleasant Symptoms}

The Theory of Unpleasant Symptoms includes three components: (i) the factors that influence the symptom; (ii) the experience of the symptom; and (iii) the performance that is affected by the symptom. ${ }^{92}$

For the first component, three factors are identified to be influencing the symptom experience; the physiological, the psychological, and the situational factors (Figure 3).$^{43}$ It is also acknowledged that the factors can relate to one another over and above their individual relationships to the symptom. ${ }^{43}$ The physiological factors can have an impact on the body's physiological functions. These can include normal and pathological body functioning, anatomi$\mathrm{cal} /$ structural, genetic, and pharmacological variables. The psychological factors include the individuals' cognition, mood or mental state, affective reactions to illness or possible meaning of the symptom..$^{43}$ The situational factors are the external aspects, such as social and physical environment, and lifestyle behaviours that might have an impact on the patient's experience and reporting of the symptom. Situational factors can be marital status, culture, temperature, light and availability and access to health care, social support, exercise, diet and fluid management. ${ }^{43,92}$

The second component of the theory is the symptom experience and comprises of four dimensions: duration, intensity, distress, and quality (Figure 3). ${ }^{92}$ In the developed and new version of the theory, the dimension of duration was changed to time dimension. ${ }^{43}$ For this thesis the time dimension will be used. 


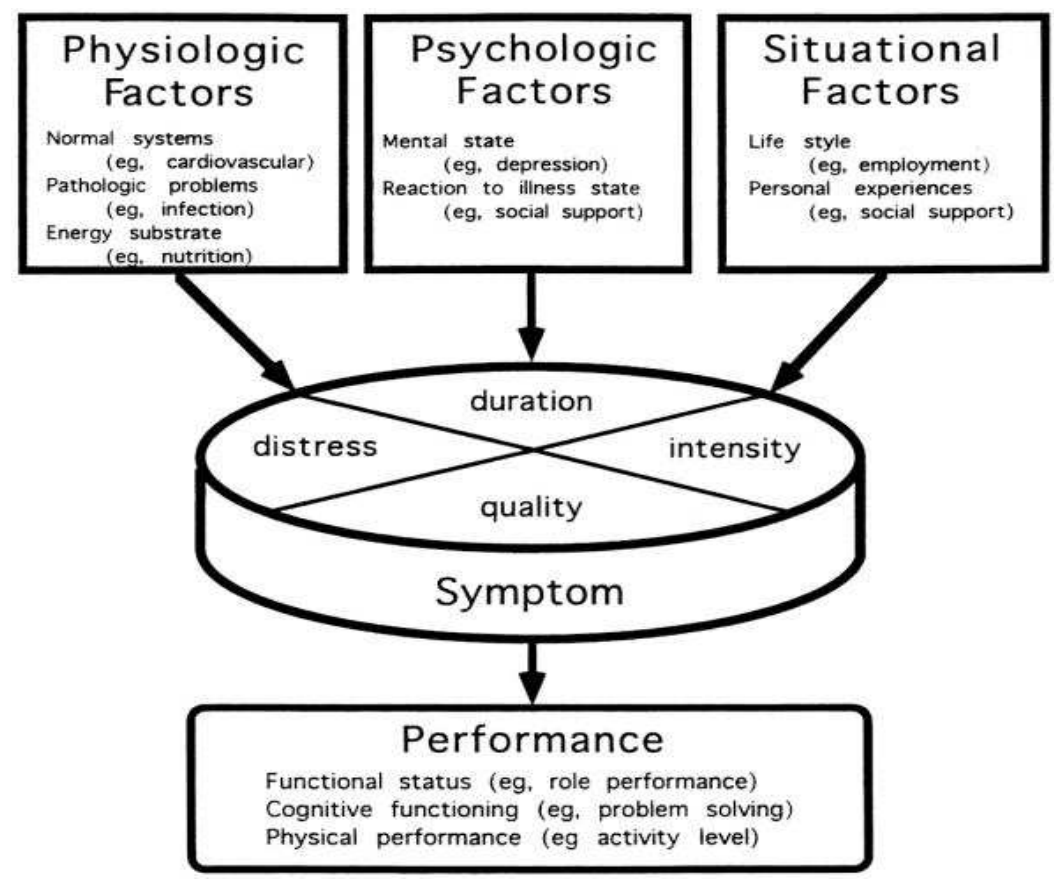

Figure 3. The original Theory of the Unpleasant Symptoms showing factors that can affect the four dimensions of the symptom and the symptom that can have an influence on performance. ${ }^{92}$ Reprinted with permission.

The time dimension describes the frequency with which a symptom occurs, the duration of a symptom, and pattern of the symptom occurrence. ${ }^{37,43}$ The symptom dimension intensity refers to the strength of the symptom and can be measured by self-reporting on a numeric rating scale or visual analogue scale (VAS) (Figure 3). Symptom distress is the degree to which the patient is bothered by the symptom. ${ }^{43}$ Distress can be measured qualitatively using interviews or quantitatively by using scales. The quality of a symptom is what the symptom is described to feel like and its associated discomfort. ${ }^{43}$ It can include description of the location of the sensation and how the patient responds to an intervention. The quality description is often specific and portrays the symptom's unique na- 
ture and can be expressed in open-ended descriptions or checklists of descriptive characteristics. $^{43}$

The third component, the performance, is proposed to be influenced by the symptom experiences (Figure 3). ${ }^{43}$ The performance can include the functional performance, such as the activities of daily living, physical activity, and social interaction and the cognitive performance, such as thinking and concentrating. This component is not studied in this thesis. Before planning an intervention study, we first need to focus on and increase the evidence about thirst in patients with HF by exploring relevant theory, identifying the factors of an possible intervention and to define the appropriate outcome measurement. ${ }^{24}$

This thesis focused on two of the components according to the Theory of Unpleasant Symptoms: the influencing physiological, psychological and the situational factors that can affect the thirst experience, and the experience of thirst, including the dimensions of time, intensity, distress, and quality. The Theory of Unpleasant Symptoms lack an important aspect that evaluates the temporal characteristics of a symptom, and describes the course and change of a symptom over time. ${ }^{91}$ For the evaluation of temporal patterns of thirst, the trajectory was included as part of the time dimension. A trajectory can reflect possible changes in the thirst experience over time, but also identify factors that might be related to the thirst experience. ${ }^{91}$ The variables chosen for the factors were based on previous knowledge about thirst and thirst in patients with HF. 3,11,20,47 An overview of the components chosen in this thesis are presented in table 2. 
Table 2. Description of the dimensions of thirst, and the factors of interest that can affect the experience of thirst in patients with heart failure.

\begin{tabular}{|c|c|c|}
\hline Component & & Description \\
\hline \multicolumn{3}{|l|}{ Dimensions } \\
\hline & Thirst time & $\begin{array}{l}\text { How often thirst occurs (frequency), and the course of } \\
\text { thirst over time (trajectory) }\end{array}$ \\
\hline & Thirst intensity & The strength of the thirst \\
\hline & Thirst distress & The degree to which the patient is bothered by the thirst \\
\hline & Thirst quality & How thirst feel like and its associated discomfort \\
\hline \multicolumn{3}{|l|}{ Factors } \\
\hline & Physiological & $\begin{array}{l}\text { Physiological variables; illness/disease, physiology (de- } \\
\text { hydration, neurohormal), pharmacological treatment, age, } \\
\text { gender }\end{array}$ \\
\hline & Psychological & $\begin{array}{l}\text { Individual variables; affective state (stress) and mood } \\
\text { (level of anxiety and depression) }\end{array}$ \\
\hline & Situational & $\begin{array}{l}\text { External variables; self-care behaviour in heart failure, } \\
\text { fluid restriction, time of day, marital status }\end{array}$ \\
\hline
\end{tabular}

\section{Rationale}

As previously described in the background, research has shown that patients with HF can be troubled by thirst. ${ }^{11,20}$ Patients described thirst as a struggle and they were thinking about their thirst the whole day. ${ }^{10}$ However, studies performed about thirst in patients with HF have not examined thirst as a primary outcome measure. ${ }^{11}$ There is none, or little information about the prevalence of thirst and the thirst intensity and thirst distress, or how patients are affected by thirst. Little is also known about what factors that might affect the thirst experience. By examining thirst trajectories, one can display changes in thirst over time and help to identify those with troublesome thirst. The possible significance attached to thirst by the patient strengthens the need for the healthcare professionals to assess thirst, target possible factors for thirst and help the patient to manage troublesome thirst. Because of the lack of knowledge about thirst in patients with HF 
health-care professionals may fail to identify those patients with thirst and help them to relieve troublesome thirst.

In order to support patients with HF with troublesome thirst, deeper understanding is needed on how thirst is experienced by describing the thirst time, thirst intensity, thirst distress, and the thirst quality. Enhanced knowledge is also needed to understand what factors increase thirst. The Theory of the Unpleasant Symptoms will serve as a model to integrate information about the thirst experience and factors related with thirst. Research on both the thirst experience, thirst trajectories and possible factors for thirst is needed to develop strategies on how to prevent and relieve thirst in patients with HF. 


\section{AIMS}

The aim of this thesis was to describe the thirst experience of patients with HF and describe the relationship of thirst with physiological, psychological and situational factors. The goal was to contribute to the improvement of the care by identifying needs and possible approaches to prevent and relieve thirst in patients with HF.

The specific aims of the studies were:

I. To compare the intensity of thirst in elderly patients with and without $\mathrm{HF}$ and to evaluate if thirst relates to the health-related quality of life and indices of the fluid balance.

II. To describe the trajectory of thirst during an 18-month period and identify variables associated with persistent thirst in patients with HF.

III. To describe changes in thirst intensity and determine factors associated with high thirst intensity during optimization of HF medication at the outpatient HF clinic.

IV. To examine thirst intensity and thirst distress trajectories in patients with HF from the hospital admission to four weeks after discharge to identify relevant contributors of thirst intensity and thirst distress over time. 


\section{METHODS}

\section{Design}

This thesis is based on four studies using quantitative methods to describe thirst and the relationship with relevant factors for thirst in patients with HF (Table 3). Study I has a cross-sectional design with between-group comparisons. Study II used available data from the $\mathrm{COACH}$ (Coordinating study evaluating Outcomes of Advising and Counselling in Heart failure) study. ${ }^{93} \mathrm{COACH}$ was a multicentre randomized, controlled trial designed to compare basic and intensive support to standard treatment in patients with HF. Data for our research question in this thesis were prospectively analysed. Study III and IV had a prospective observational design with between-group (III, IV) and within-group comparisons (III).

Table 3. Overview of study design and setting.

\begin{tabular}{|c|c|c|c|c|}
\hline Variable & Study I & Study II & Study III & Study IV \\
\hline Design & Cross-sectional & $\begin{array}{l}\text { Prospective, } \\
\text { observational }\end{array}$ & $\begin{array}{l}\text { Prospective, } \\
\text { observational }\end{array}$ & $\begin{array}{l}\text { Prospective, } \\
\text { observational }\end{array}$ \\
\hline Patients & 48 & 649 & 69 & 30 \\
\hline Setting & Hospital & $\begin{array}{l}\text { Outpatient } \\
\text { HF clinic }\end{array}$ & $\begin{array}{l}\text { Outpatient } \\
\text { HF clinic }\end{array}$ & $\begin{array}{l}\text { Hospital and } \\
\text { patients home }\end{array}$ \\
\hline Time & $\begin{array}{c}2009 \\
\text { (Feb-July) }\end{array}$ & $\begin{array}{l}2002 \text { (Oct)- } \\
2005 \text { (Feb) }\end{array}$ & $\begin{array}{l}2012 \text { (Sept)- } \\
2014 \text { (Aug) }\end{array}$ & $\begin{array}{l}2012 \text { (Jan)- } \\
2014 \text { (Aug) }\end{array}$ \\
\hline
\end{tabular}

\section{Setting}

Data was collected from patients while they were in the hospital (I, II, IV) and visiting an outpatient HF clinic (II-IV) or was followed at home (IV) (Table 3). One hospital (I, IV) was situated in a medium-sized Swedish city, and two other hospitals (III) in a big-city area. For study II, the hospitals in which the patients were recruited were located in seventeen cities in The Netherlands. 


\section{Sample}

\section{Sampling}

Patients were identified by a research nurse (I, II, IV) and HF nurse (III) by looking at a computer list with admitted patients to the clinic (I, IV), and by a list of scheduled visits to HF clinic (III). A consecutive sampling process was selected for inclusion (I, III-IV). Patients who were diagnosed with HF according to guidelines and who had a reduced left ventricular ejection fraction $(\leq 50 \%)$ were eligible.

Additional inclusion criteria for studies I, III, and IV were:

- Age $\geq 60$ years (III, IV) and $\geq 65$ years (I)

- Decompensated HF at hospital admission (I, IV), patients admitted to hospital to receive treatment for illness, but not diagnosed with HF and with no symptoms of dyspnoea or leg oedema (I), referred for up-titration of HF pharmacological treatment, with signs and symptoms of HF (III)

Exclusion criteria were:

- Other conditions with risk for thirst: diabetes type 1 (I, III, IV), ${ }^{3}$ renal failure with dialysis, ${ }^{26,28}$ and patients with oxygen treatment ${ }^{94}$ (III, IV) or severe/life threatening condition that prevented patients from participating, and difficulties to understand and speak the Swedish language.

Patients who met the inclusion criteria were approached in the study the morning after hospital admission (I), during daytime after admission (IV), or at daytime (II, III). All patients received both verbal and written information about the study, and patients who agreed to participate signed an informed consent.

For study II, data was used from patients who were included in the $\mathrm{COACH}$ study. The inclusion criteria for $\mathrm{COACH}$ was 18 years of age or older and hospital admission for HF, and being able to speak and understand Dutch. Exclusion 
criteria were participation in another study and a recent or planned invasive cardiac intervention. ${ }^{93}$ Only patients who had data available on thirst were included in the analysis. This meant that only patient who completed the revised HF compliance scale with the subscale "compliance with fluid restriction" were included. In the scale, patients were asked if they have problems complying with fluid restriction and why, and one possible answer was "thirst". Patients were included in study II if they completed the subscale "compliance with fluid restriction" on $\geq 3$ of the 4 follow-up occasions. A total of 102 patients were excluded because they completed the subscale "compliance with fluid restriction" fewer than three times, and another 272 patients died during the study period. A total of 649 patients were included in study II (Table 4). A large number of patients were excluded due to the exclusion criteria (I, III, IV).

Table 4. Description of patients' flow in the studies

\begin{tabular}{lcccc}
\hline & $\begin{array}{c}\text { Study I } \\
\mathrm{a} / \mathrm{b}\end{array}$ & Study II & Study III & Study IV \\
\hline Eligible & $41 / 164$ & 1023 & 148 & 119 \\
Excluded & $18 / 138$ & 374 & 79 & 74 \\
Declined & $-/ 1$ & - & - & 15 \\
Included & $23 / 25$ & 649 & 69 & 30 \\
Lost to follow-up & - & - & 3 & 5 \\
Completed & $23 / 25$ & 649 & 66 & 25 \\
\hline
\end{tabular}

a, patients with heart failure; b, patients without heart failure

\section{Sample size}

An estimation of a sample size was performed based on a previous study, which showed that the standard deviation, when a VAS scale $(0-100 \mathrm{~mm})$ was applied to thirst intensity, did not exceed $25 \mathrm{~mm}^{84,85}$ Power analysis for a randomized study showed that 50 patients would be needed to detect a clinically important difference in thirst intensity of $20 \mathrm{~mm}(\mathrm{P}<0.05)$ with a confidence of $80 \%$. 


\section{Participants}

The mean age of the patients included ranged between 69 years (II) to 81 years (I, IV). In studies II and III there were more men than women, and in study I, there were more women. Between 32-62\% were cohabiting (Table 5). Most of the patients admitted to hospital were in NYHA class III (I, IV) and patients visiting an outpatient clinic were in NYHA class II (II, III) (Table 5). The most common comorbidities were atrial fibrillation, hypertension and coronary artery disease.

Table 5. Overview of demographic and clinical characteristics, and comorbidities for study participants.

\begin{tabular}{|c|c|c|c|c|c|}
\hline \multirow[b]{2}{*}{ Variable } & \multicolumn{2}{|c|}{ Study I } & \multirow{2}{*}{$\begin{array}{r}\text { Study II } \\
(n=649)\end{array}$} & \multirow{2}{*}{$\begin{array}{l}\text { Study III } \\
(n=69)\end{array}$} & \multirow{2}{*}{$\begin{array}{c}\text { Study IV } \\
(n=30)\end{array}$} \\
\hline & $1(n=23)$ & $2(n=25)$ & & & \\
\hline Age & $81 \pm 7$ & $80 \pm 8$ & $69 \pm 12$ & $73 \pm 7$ & $81 \pm 7$ \\
\hline Women, $\%$ & 65 & 72 & 38 & 17 & 47 \\
\hline Cohabiting, $\%$ & 37 & 32 & 62 & 57 & 53 \\
\hline Systolic BP, mm Hg & $122 \pm 20$ & $133 \pm 14$ & $119 \pm 21$ & $123 \pm 19$ & $135 \pm 29$ \\
\hline Diastolic BP, $\mathrm{mm} \mathrm{Hg}$ & $70 \pm 10$ & $69 \pm 10$ & $69 \pm 12$ & $75 \pm 12$ & $75 \pm 13$ \\
\hline BMI, $\mathrm{kg} / \mathrm{m}^{2}$ & - & - & $27 \pm 5$ & $27 \pm 5$ & $26 \pm 6$ \\
\hline $\mathrm{LVEF}, \%$ & $32 \pm 12$ & - & $33 \pm 14$ & $32 \pm 9$ & $37 \pm 12$ \\
\hline NYHA class II, \% & - & - & 56 & 54 & - \\
\hline NYHA class III, \% & 87 & - & 42 & 45 & 93 \\
\hline NYHA class IV, \% & 13 & - & 2 & 1 & 7 \\
\hline Atrial fibrillation, $\%$ & 61 & 12 & - & 59 & 60 \\
\hline Hypertension, \% & 30 & 44 & 41 & 35 & 67 \\
\hline Coronary artery disease, $\%$ & 13 & 16 & 39 & 35 & 37 \\
\hline Cardiomyopathy, \% & 4 & 0 & 24 & 9 & 3 \\
\hline Valvular disease, $\%$ & - & - & 9 & 17 & 3 \\
\hline COPD, $\%$ & - & - & 24 & 10 & 17 \\
\hline Stroke, \% & - & - & 8 & 9 & 10 \\
\hline Malignancy, \% & 21 & 28 & - & 15 & 17 \\
\hline Diabetes $1, \%$ & 0 & 0 & 10 & 0 & 0 \\
\hline Diabetes 2,\% & 0 & 0 & 14 & 22 & 7 \\
\hline Renal disease, $\%$ & 17 & 8 & 6 & 7 & 3 \\
\hline Depression, \% & 17 & 24 & - & 1 & 7 \\
\hline
\end{tabular}

Study I: group 1= heart failure patients, 2= non-heart failure patients; HF, heart failure; BP, blood pressure; BMI, body mass index; LVEF, left ventricular ejection fraction; NYHA, New York Heart Association; COPD, chronic obstructive pulmonary disease.

Values are presented as mean $\pm \mathrm{SD}$, median (IQR), or \%. 


\section{Data collection and measurements}

The research nurse (I, II, IV) and the HF nurses (III) collected data. Patients who needed help to read the questions and/or fill in the questionnaire were assisted by the research nurse or HF nurse (I-IV). Data collection was completed at hospital admission (I), at one, six, twelve and eighteen months follow-up visits at an HF outpatient clinic (II), at first visit to an outpatient HF clinic, and at the end of the HF up-titration program (III), and at hospital admission, hospital discharge, two and four weeks after hospital discharge (IV) (Fig 4). In study I, data was collected between 7:00 and 8:00 AM, before breakfast and before taking any daily medication, in order to prevent their influence on thirst. In studies II-IV, data were collected in the daytime.

Data was collected by self-administered questionnaires and sampling of blood (II-IV), urine (I) and saliva (III) for analyses of biochemical parameters known to be associated with thirst, the severity of the HF condition and of stress (Table 6). Blood, urine and saliva sampling were taken after patients responded to the questionnaires (I-IV). The saliva sampling was taken before blood sampling (III). The blood and saliva samples were analyzed at the Study Center, Karolinska University Laboratory, Stockholm, Sweden (III, IV). In all studies, background data on patient socio-demographic and clinical characteristics, and comorbidities were collected from hospital medical records. 


\section{Study I}

Data collection $\begin{aligned} & \text { Admission } \\ & \text { to hospital }\end{aligned}$

Study II

Time

\begin{tabular}{ccccc}
\cline { 2 - 5 } Data collection & Month 1 & Month 6 & Month 12 & Month 18 \\
follow-up & follow-up & follow-up & follow-up \\
outpatient clinic & outpatient clinic & outpatient clinic & outpatient clinic
\end{tabular}

\section{Study III}

Time

Up-titration of heart failure medical therapy

Data collection $\quad \begin{gathered}\text { Baseline } \\ \text { outpatient clinic }\end{gathered}$

End

outpatient clinic

\section{Study IV}

Time

$\begin{array}{ccccc}\text { Data collection } & \begin{array}{c}\text { Admission } \\ \text { hospital }\end{array} & \begin{array}{c}\text { Discharge } \\ \text { hospital }\end{array} & \begin{array}{c}\text { 2-weeks after } \\ \text { discharge home }\end{array} & \begin{array}{c}\text { 4-weeks after } \\ \text { discharge home }\end{array}\end{array}$

Figure 4. Data collection time points in the studies. 
Table 6 Measurements for the thirst dimensions and the physiological, psychological and situational factors examined for thirst in the thesis.

\begin{tabular}{|c|c|c|}
\hline & Measurement & Study \\
\hline \multicolumn{3}{|c|}{ Thirst dimensions } \\
\hline Time & Frequency, thirst trajectory & II, III, IV \\
\hline Intensity & Visual analogue scale $(100 \mathrm{~mm})^{95}$ & I, III, IV \\
\hline Distress & Thirst distress scale (9 item lickert scale $)^{96}$ & III, IV \\
\hline Quality & Description of thirst ${ }^{96}$ & III, IV \\
\hline \multicolumn{3}{|l|}{ Factors } \\
\hline \multirow[t]{9}{*}{ Physiological } & P/Sodium & I-IV \\
\hline & P/Urea, NT-proBNP & II-IV \\
\hline & S/Osmolality & III-IV \\
\hline & P/Aldosterone & III \\
\hline & $\mathrm{U} /$ Specific gravity, U/Colour & \\
\hline & Age, Gender & I-IV \\
\hline & NYHA-class & I-IV \\
\hline & Pharmacological treatment & I-IV \\
\hline & Anxiety/depression (1 item in EQ-5D) $)^{97}$ & I \\
\hline \multirow[t]{3}{*}{ Psychological } & Depressive symptoms (CES-D scale) ${ }^{98}$ & II \\
\hline & Feeling anxiety and depressed ( 2 item lickert scale) & III, IV \\
\hline & Stress (Sa/Cortisol) & III \\
\hline \multirow[t]{4}{*}{ Situational } & HF Self-Care behaviour (9 item lickert scale) ${ }^{99}$ & III, IV \\
\hline & Fluid restriction & II-IV \\
\hline & Marital status & I-IV \\
\hline & Time of day & I, III, IV \\
\hline
\end{tabular}

P, plasma; S, serum; U, urine; Sa, saliva; NT-proBNP, N-terminal of the prohormone brain natriuretic peptide; NYHA, New York Heart Association functional classification; EQ-5D, EuroQol five healthdimensions questionnaire; $\mathrm{HF}$, heart failure.

\section{Dimensions examined of thirst}

\section{Thirst time}

The frequency of thirst was measured by how often thirst was present at followups during the study (II). Trajectories were displayed using data on the presence of thirst for each follow-up (II). Trajectories were also displayed using data on thirst intensity and thirst distress for each follow-up with (IV).

\section{Thirst intensity}

Thirst intensity was measured by using the visual analogue scale (VAS; 0-100 $\mathrm{mm}$ ) (I, III, IV). ${ }^{95}$ The patients were asked to grade their thirst intensity on a 100 
mm long horizontal line by marking a cross on the line. The left side of the line was marked "no thirst" and the right side of the line was marked "worst possible thirst". The VAS has been used in studies to measure pain and quality of life as well as thirst intensity in different populations. ${ }^{31,41,95,100}$ It has been validated for patients with $\mathrm{HF}^{95}$

\section{Thirst distress}

Thirst distress was measured with the Thirst Distress Scale for patients with HF (III, IV). ${ }^{96}$ The Thirst Distress Scale for patients with HF is a nine item, fivepoint Likert scale. Patients were asked to rate statements about thirst from 1 (strongly disagree) to 5 (strongly agree). The total score ranges from 9 to 45 , with higher scores indicating higher thirst distress. For this thesis, the total thirst distress scores were classified as no thirst distress (score 9), mild thirst distress (score 18), moderate thirst distress (score 27), strong thirst distress (score 36) and severe thirst distress (score 45). Patients were defined as no to mild thirst distress (scores 9-18) and moderate to severe thirst distress (scores 19-45). For study III, the scale had a Cronbach's alpha of 0.92 and for study IV 0.85 .

No instrument measuring thirst distress for Swedish-speaking patients with HF was found, and therefore the Thirst Distress Scale for patients with HF was developed from the original six item scale for English (USA)-speaking patients with renal failure. ${ }^{26}$ The scale was translated and back translated using a professional translator of American origin (member of the Association of Professional Translators, Sweden). ${ }^{101,102}$ She was blinded to the original scale in order not to influence the translation. ${ }^{102,103}$ The scale was adapted for patients with HF using an expert group with one cardiologist, one dietician, and two nurses with $\mathrm{PhD}$ with knowledge about HF and two HF nurses, assessed the scale as well as ten patients with HF. ${ }^{102,104}$ One item in the original scale was removed because it was very similar to another item. ${ }^{104}$ Four new items with relevance for patients with HF proposed by the expert group were added (items $2,5,8$, 9, see below 
dimension thirst quality). This work was done with permission from Professor Welch, who developed the original Thirst Distress Scale.

For evaluation of the Thirst Distress Scale for patients with HF, content validity and reliability were assessed by item-total and inter-item correlations, exploratory factor analysis and Cronbach's alpha (III)..$^{96}$ The item-total correlation of items and the inter-item correlations showed sufficient to strong correlations $(r=0.61$ and 0.82 ; and $r=0.34-0.87)$. The factor analyses showed that the scale included two factors; a "general thirst sensation" (items 1-3, 7-9; Cronbach's $\alpha=0.92$ ), and "thirst with mouth sensations" (items 4-6; $\alpha=0.82$ ) (III). ${ }^{96}$ For study III, the internal consistency of the Thirst Distress Scale for patients with HF was high $(\alpha=0.92)$, and for study IV good $(\alpha=0.85)$.

\section{Thirst quality}

The quality of thirst was described with statements what thirst feels like and its associated discomfort by using the Thirst Distress Scale for patients with HF (see previous page, Thirst distress) (III, IV). ${ }^{96}$ The scale is a 5 -point Likert scale and patients were asked to rate statements about thirst from 1 (strongly disagree) to 5 (strongly agree). Scores between 1 and 2 were categorized as no or little agreement to the item description of thirst, and scores between 3 and 5 were categorized as moderate to strong agreement to the item description. Patients with moderate to strong agreement to the description are presented as number of patients (\%). The thirst quality descriptions are: (1) My thirst bothers me a lot; (2) My thirst bothers me daily; (3) I am very uncomfortable when I am thirsty; (4) My mouth feels like sandpaper when I am thirsty; (5) My mouth feels dry when I am thirsty; (6) My saliva is very thick when I am thirsty; (7) When I drink less water, my thirst gets worse; (8) I am so thirsty I could drink water uncontrollably; and (9) My thirst feels insurmountable. 


\section{Factors related to thirst}

\section{Situational}

Data was collected on marital status (I-IV), and time of the day when thirst was measured (I, III). Information about if patients were having a fluid restriction and the amount of fluid restriction was collected by asking the patients (II-IV). By using the European Heart Failure Self-care Behaviour scale (EHFScB-9), data was collected on self-care behaviours that patients with HF are recommended to perform to maintain life, healthy functioning and well-being (III, IV). ${ }^{99}$ Patients were asked to respond to 9 items rated on a five-point Likert scale from 1 (I completely agree) to 5 (I completely disagree). The scores were computed to the new reversed and standardized scores (0-100). ${ }^{105}$ The EHFScB-9 has been used in many studies with HF patients and it has been translated to several languages. The EHFScB-9 is considered as a valid and reliable instrument. For study III, the scale had a Cronbach's alpha of 0.73 and for study IV, 0.74 .

\section{Physiological}

To evaluate the presence of dehydration the serum osmolality, plasma sodium, aldosterone, and plasma urea were measured (I-IV). Urine samples were collected to evaluate the hydration status by measuring the specific gravity in urine and by a standardized visual assessment of the urine colour (I). The urine sample was placed directly after collection in a clear test tube and held against an 8numbered urine colour chart with a white background. The assessment was performed under the same lightning conditions. The colour of the urine was assessed on the chart ranging from pale straw (urine colour=1) to greenish brown (urine colour $=8) .{ }^{106}$ Urine colours between 3 to 8 indicate dehydration. ${ }^{107}$ The urine specific gravity was determined by using the Urisys 1100 (Roche Diagnostics Scandinavia, Bromma, Sweden) along with the chemistrip Combur ${ }_{10}$ Test $\mathrm{M}$ urine test. The readings from the analyser ranged from 1.000 to 1.030 in 0.005 intervals. 
For the evaluation of the HF severity, the NYHA functional classification ${ }^{12}$, 108 was measured by interviewing the patient and the left ventricular ejection fraction by echocardiography (I-IV). ${ }^{12}$ Plasma NT-proBNP was measured to confirm the HF diagnosis and to evaluate the severity of $\mathrm{HF}^{12}$

Ten symptoms in patients with HF were examined for their presence by asking the patients: dyspnoea during rest, dyspnoea lying down, dyspnoea during exercise, fatigue, cough, and dry cough, ankle edema after waking up, ankle edema at daytime, difficulty sleeping, decreased appetite (II). The total number of symptoms was summed up.

Pharmacological treatment on HF medication (I-IV) and medication that could affect thirst (I, III, IV) was collected from hospital medical records or from interviews with the patient.

\section{Psychological}

The Center for Epidemiological Studies Depression Scale was used to assess depressive symptoms (II). ${ }^{98}$ The scale consists of 20 items and measures the presence of depressive feelings and behaviours. Patients are asked to rate on a fourpoint Likert scale ranging from 0 (rarely or none of the time) to 3 (most or all the time). The total score ranges from 0 to 60 points, with higher scores indicating higher presence of depressive symptoms. A score of 16 and higher indicates the presence of depressive symptoms. ${ }^{98}$ The Center for Epidemiological Studies Depression Scale is a well-used scale to measure depressive symptoms in different populations.

One item in the EuroQol five health-dimensions questionnaire was used to measure anxiety/depression (I). Patients were asked to classify the severity or problem with anxiety/depression into one of three categories: no problems, some problems, and extreme problems. Patients with some problems and extreme problems were labelled to have anxiety/depression (I). The EuroQol five healthdimensions questionnaire was chosen because it is a generic instrument and can therefore be used for patients with different conditions and diseases. The Eu- 
roQol five health-dimensions questionnaire has been found to be a valid and reliable instrument. ${ }^{109-111}$

To measure the level of feeling anxiety and feeling depressed, a two-item Likert scale was developed for the thesis (III, IV). Patients were asked to rate whether they have felt anxious and depressed during the last few days between 1 (strongly disagree) to 5 (strongly agree). Scores between 3 to 5 were categorized as moderate to severe feeling of anxiety and feeling depressed. The scale has been assessed for face validity by five patients who considered the scale to be clear and relevant (IV).

Stress was measured by sampling of saliva cortisol (Table 6) (III). ${ }^{112}$ The saliva samples were analyzed at the Study Center, Karolinska University Laboratory, Stockholm, Sweden.

\section{Data analysis}

Data analyses were performed using StatView SE + Graphics (Abacus Concepts, Inc., USA) (I), and IBM Statistical package for social sciences version 20 (II), 22 (III), and version 23 (IV) (SPSS, Chicago, Illinois, USA).

Cronbach's $\alpha$ coefficient was used to calculate the reliability for the Thirst Distress Scale for patients with HF (III, IV). ${ }^{113}$ Continuous data showing a normal distribution are presented as the mean and standard deviations (SD), and data with skewed distribution are presented as the median and interquartile range (IQR). Categorical data are presented by frequencies and percentage (\%). The level of statistical significance was set at $P<.05$ (I-IV).

\section{Procedures}

Prior data analyses patients were dichotomized into persistent and nonpersistent thirst groups (II), high and low thirst intensity groups (III, IV), and into high and low thirst distress groups (Table 7) (IV). Because there are no cut-off 
values for low and high thirst intensity and thirst distress, the median values of the samples were used (III, IV). To examine if thirst intensity and thirst distress trajectories differ by potential contributors, including gender, fluid restriction, age, body mass index (BMI), serum urea, and feeling anxious or depressed, each variable was dichotomized into two groups for each follow-up (IV). Age and BMI were dichotomized by the mean value, and serum urea by the median value. Fluid restriction was dichotomized by the absence or presence of fluid restriction; anxious by the absence or presence of feeling anxious using a cut point of 3 (Likert scale 1-5); depressed by the absence or presence of feeling depressed (cut point 3). Gender was dichotomized into groups of women and men.

Table 7 Patients with HF were dichotomized in order to compare groups (II-IV)

\begin{tabular}{|c|c|c|c|}
\hline & Study II & Study III & Study IV \\
\hline Groups & $\begin{array}{l}\text { 1) Persistent thirst } \\
\text { 2) No persistent thirst }\end{array}$ & $\begin{array}{l}\text { 1) High thirst intensity } \\
\text { 2) Low thirst intensity }\end{array}$ & $\begin{array}{l}\text { 1.1) High thirst intensity } \\
\text { 1.2) Low thirst intensity } \\
\text { 2.1) High thirst distress } \\
\text { 2.2) Low thirst distress }\end{array}$ \\
\hline Dichotomized by & $\begin{array}{l}\text { Occurrence of thirst } \\
\text { during the study } \\
\text { 1) } \geq 2 \text { of } 4 \text { times } \\
\text { 2) } \leq 1 \text { times }\end{array}$ & $\begin{array}{l}\text { Median thirst intensity at } \\
\text { the end of the study } \\
\text { 1) } \geq 21 \mathrm{~mm} \\
\text { 2) }<21 \mathrm{~mm}\end{array}$ & $\begin{array}{l}\text { Median thirst intensity at } \\
\text { admission } \\
1.1)>39 \mathrm{~mm} \\
1.2) \leq 39 \mathrm{~mm} \\
\text { Median thirst distress at } \\
\text { admission } \\
2.1)>22 \text { scores } \\
2.2) \leq 22 \text { scores }\end{array}$ \\
\hline
\end{tabular}

\section{Analyses}

A summary of the data analyses in the studies is presented in Table 8. Univariate analyses were used to identify variables associated with thirst (I, II, III).

Study I: Analyses were performed between the patients with and without HF. Variables of interest for thirst intensity were analysed with one-, two- or three-way ANOVA. Prior to the analysis data on thirst intensity was square-root 
transformed to achieve a normal distribution. The distribution of urine colour was analysed with contingency table analysis.

Study II: With the Cochran Q test, the occurrences of thirst were compared at each follow-up with the occurrence of thirst at 1 month after hospital discharge. Thirst trajectories were examined by summarizing the occurrences of thirst (yes/no) in each follow-up examination at 1, 6, 12, and 18 months. Descriptive statistics were used to describe the study population at baseline depending on the presence or absence of persistent thirst. Univariate analyses were used to identify variables associated with persistent thirst. Variables with a difference of $P<.15$ were entered in a logistic regression analysis. A higher probability of persistent thirst was indicated by an odds ratio of $>1$ and a lower probability by an odds ratio of $<1$.

Study III: Changes in thirst intensity between baseline $\left(\mathrm{y}_{1}\right)$ and end $\left(\mathrm{y}_{2}\right)$ were calculated by using delta $(\Delta) ; \Delta=\mathrm{y}_{2}-\mathrm{y}_{1}$. Univariate analyses were performed to identify variables associated with high thirst intensity. Differences within groups were analysed at baseline and end and between the patients with high and low thirst intensity. Variables with a difference of $P<.05$ were entered in a logistic regression analysis. A logistic regression analysis was performed to identify factors associated with high thirst intensity at the end. A higher probability of high thirst intensity was indicated by an odds ratio of $>1$ and a lower probability by an odds ratio of $<1$.

Study IV: To study the trajectories of thirst intensity and thirst distress over the four follow-ups between groups, the growth modelling was applied using linear mixed analysis. Thirst intensity and thirst distress were the outcome variables and age, gender, BMI, serum urea, fluid restriction, feeling depressed and feeling anxious were the covariates. For this study, we assumed that the care at hospital and the care in home settings are different. To avoid interference on thirst of specific factors during hospitalization and home care, a transition time-point was centered between hospital discharge and two weeks after discharge (intercept). Results on thirst intensity and thirst distress are presented as mean values as ap- 
propriate for the linear mixed analysis. Estimates with $95 \%$ confidence intervals were calculated for each growth model.

Table 8. Overview of study specific analyses and their application in the studies.

\begin{tabular}{|c|c|c|c|c|c|}
\hline Method & Data & Study I & Study II & Study III & Study IV \\
\hline $\begin{array}{l}\text { Mann Whitney } \\
\text { U test }\end{array}$ & $\begin{array}{l}\text { Continuous } \\
\text { skewed dis- } \\
\text { tribution }\end{array}$ & $\begin{array}{l}\text { Between group } \\
\text { comparisons }\end{array}$ & $\begin{array}{l}\text { Between group } \\
\text { comparisons }\end{array}$ & $\begin{array}{l}\text { Between group } \\
\text { comparisons }\end{array}$ & \\
\hline Wilcoxon test & $\begin{array}{l}\text { Continuous } \\
\text { skewed dis- } \\
\text { tribution }\end{array}$ & & & $\begin{array}{l}\text { Within group } \\
\text { comparisons }\end{array}$ & \\
\hline $\begin{array}{l}\text { Independent } \\
\text { t test }\end{array}$ & $\begin{array}{l}\text { Continuous } \\
\text { normal dis- } \\
\text { tribution }\end{array}$ & & $\begin{array}{l}\text { Between group } \\
\text { comparisons }\end{array}$ & $\begin{array}{l}\text { Between group } \\
\text { comparisons }\end{array}$ & \\
\hline $\begin{array}{l}\text { Dependent } \\
\text { t test }\end{array}$ & $\begin{array}{l}\text { Continuous } \\
\text { normal dis- } \\
\text { tribution }\end{array}$ & & & $\begin{array}{l}\text { Within group } \\
\text { comparisons }\end{array}$ & \\
\hline Chi-square test & Categorical & & $\begin{array}{l}\text { Between group } \\
\text { comparisons }\end{array}$ & $\begin{array}{l}\text { Between group } \\
\text { comparisons }\end{array}$ & \\
\hline Contingency table & Categorical & $\begin{array}{l}\text { Between group } \\
\text { comparisons }\end{array}$ & & & \\
\hline McNemar test & Categorical & & & $\begin{array}{l}\text { Within group } \\
\text { comparisons }\end{array}$ & \\
\hline Cochran Q test & Categorical & & $\begin{array}{l}\text { Between group } \\
\text { comparisons }\end{array}$ & & \\
\hline $\begin{array}{l}\text { One-, two-, three- } \\
\text { way ANOVA }\end{array}$ & $\begin{array}{l}\text { Continuous } \\
\text { normal dis- } \\
\text { tribution }\end{array}$ & $\begin{array}{l}\text { Between group } \\
\text { comparisons }\end{array}$ & & & \\
\hline $\begin{array}{l}\text { Logistic regression } \\
\text { backward method }\end{array}$ & $\begin{array}{l}\text { Continuous } \\
\text { skewed dis- } \\
\text { tribution }\end{array}$ & & $\begin{array}{l}\text { Group mem- } \\
\text { bership }\end{array}$ & $\begin{array}{l}\text { Group mem- } \\
\text { bership }\end{array}$ & \\
\hline $\begin{array}{l}\text { Linear mixed } \\
\text { analysis }\end{array}$ & $\begin{array}{l}\text { Continuous } \\
\text { Categorical }\end{array}$ & & & & $\begin{array}{l}\text { Rate of change } \\
\text { Between group } \\
\text { comparisons }\end{array}$ \\
\hline
\end{tabular}




\section{Ethical considerations}

Permission for the studies was obtained from the Regional Ethical Review Board in Stockholm (I, III, IV) and the Ethics Committee of the University Medical Center of Groningen in the Netherlands (II). All patients received written and verbal information about the study and each patient gave his/her informed consent for participation. They were informed that they could withdraw their consent without any explanation or reprisal. Each patient received a code number, and a code list was kept in a fireproof safe. Data and the fireproof safe were kept in a secure office so that no unauthorized person could examine the data. This guaranteed confidentiality as much as possible.

The studies complied with the Declaration of Helsinki, which means that the studies were performed according to principals of autonomy, not harming, beneficence, justice and with respect of human rights. ${ }^{114}$ These principals were important when considering the frailty of patients with HF especially at admission to hospital with decompensated HF. Patients were asked to answer questionnaires in all the studies and this procedure could potentially be perceived as burdensome. The number of questionnaires and the number of items in the questionnaires were carefully considered prior the studies. Patients were also asked to provide blood, urine and/or saliva samples in the studies, which may cause discomfort and pain. For this reason, all patients were offered topical anaesthetic on the skin prior to blood samples. If patients had any questions regarding the study, they could call the principal investigator 


\section{RESULTS}

\section{Description of thirst dimensions}

The thirst experience was reported with the four dimensions, time, intensity, distress, and quality.

\section{Thirst time}

Thirst was reported to be present in $21 \%$ of all patients $(n=136)$ at the 1 -month follow-up, in 18\% $(\mathrm{n}=115)$ at 6-month follow up, in $16 \%(\mathrm{n}=104)$ at 12 -month follow-up, and in $17 \%(\mathrm{n}=108)$ at the 18 -month follow-up in patients at an outpatient clinic (II).

A total of $33 \%(n=212)$ reported thirst on at least one occasion. Fourteen percent $(n=91)$ of them reported thirst at one time, $6 \%(n=37)$ at two times, $6 \%$ $(n=38)$ at three times, and 7\% $(n=46)$ reported thirst at every follow-up (II). Of the patients who reported thirst during the study, $43 \%(n=91)$ reported thirst on one occasion and $57 \%(\mathrm{n}=121)$ reported thirst on two to four occasions.

Of the patients who reported thirst at the one-month follow-up were more often thirsty also at subsequent follow-up visits (months 6, 12, and 18) ( 50\%) compared to patients with no thirst at one month $(\sim 7 \% ; P<0.001)$ (II).

Trajectories for thirst were examined for the number of patients with and without thirst over the follow-ups (II). Of all patients admitted to hospital for decompensated HF $(n=649)$ and followed over 18 months, 21\% $(n=136)$ had thirst at the one-month follow-up. Of the patients who had thirst at the one-month follow-up, $34 \%(n=46)$ continued to report thirst during the rest of the study, while $32 \%(n=44)$ no longer reported thirst at all and 34\% $(n=46)$ reported thirst on two or three of the follow-up occasions (II). Persistent thirst (thirst at $\geq 2$ of 4 followups) was present in $19 \%(n=121)$ of patients. (II). 
Trajectories for thirst intensity showed that patients who were admitted to hospital with high thirst intensity decreased thirst intensity by $-4.5 \mathrm{~mm}$ per follow-up, while patients with low thirst intensity increased thirst intensity by $4 \mathrm{~mm}$ per follow-up (IV) $(\mathrm{P}=0.005$; Figure 5).

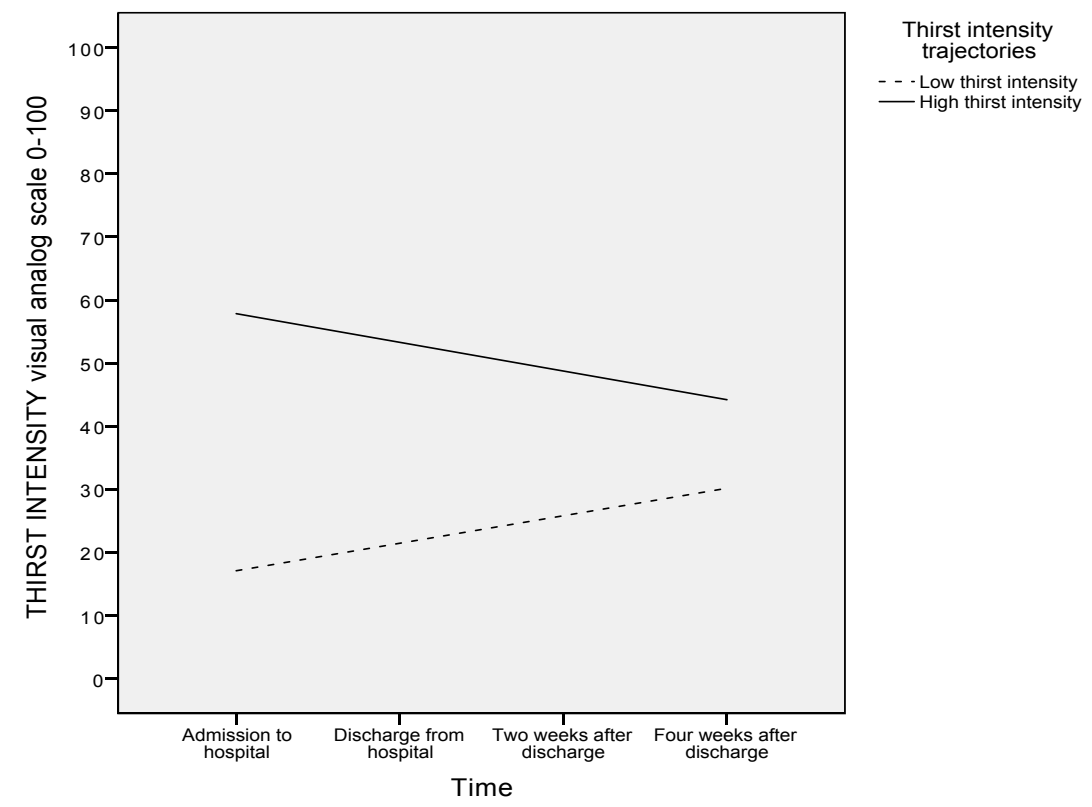

Figure 5. Thirst intensity trajectories for patients admitted to hospital with high and low thirst intensity (IV).

Thirst distress remained at a high level over time in patients admitted to hospital with high thirst distress (Figure 6). Thirst distress did not change in different ways between the patients admitted with high and low thirst distress at admission (IV). Patients with a fluid restriction had higher thirst distress over time compared to patients without fluid restriction (IV) (Figure 7). Women had a higher thirst distress over time compared to men (IV) (Figure 8). Patients who were feeling depressed had higher thirst intensity over time compared to patients who did not feel depressed (IV) (Figure 9). 


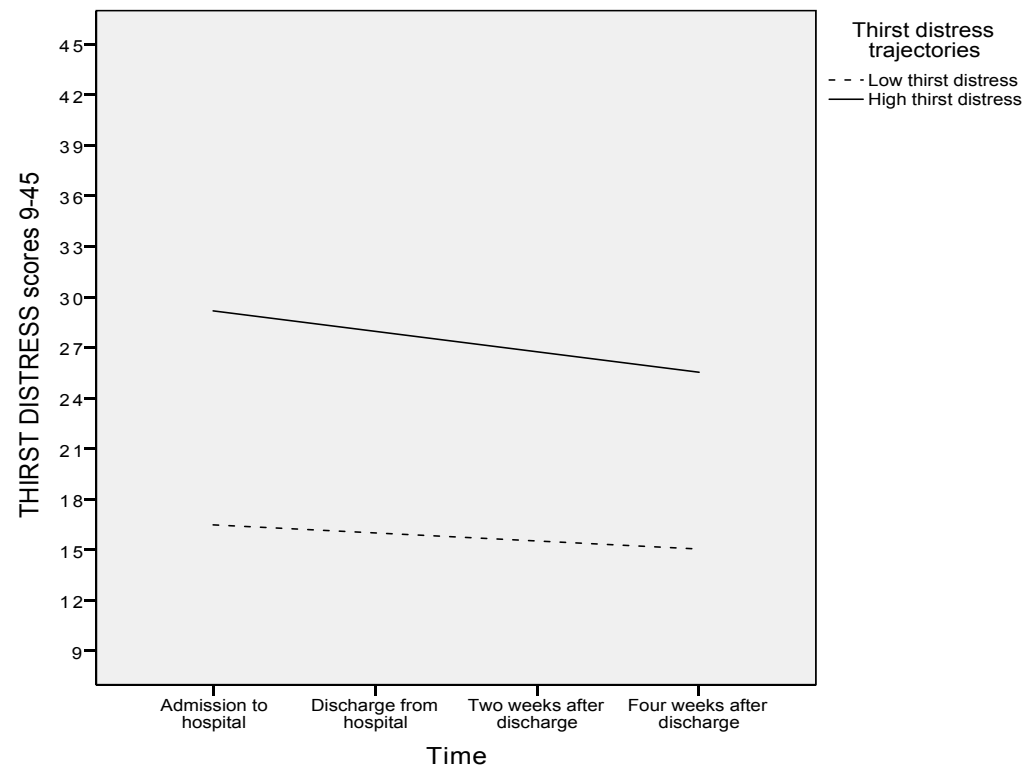

Figure 6. Thirst distress trajectories for patients admitted to hospital with high and low thirst distress (IV).

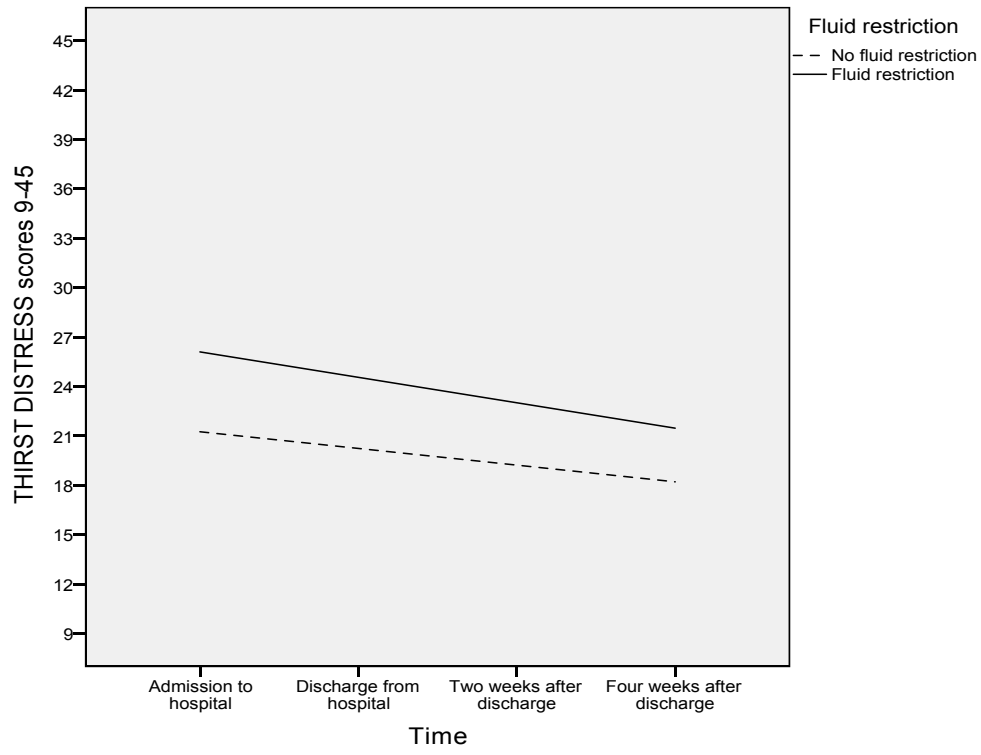

Figure 7. Thirst distress trajectories for patients with fluid restriction and no fluid restriction (IV). 


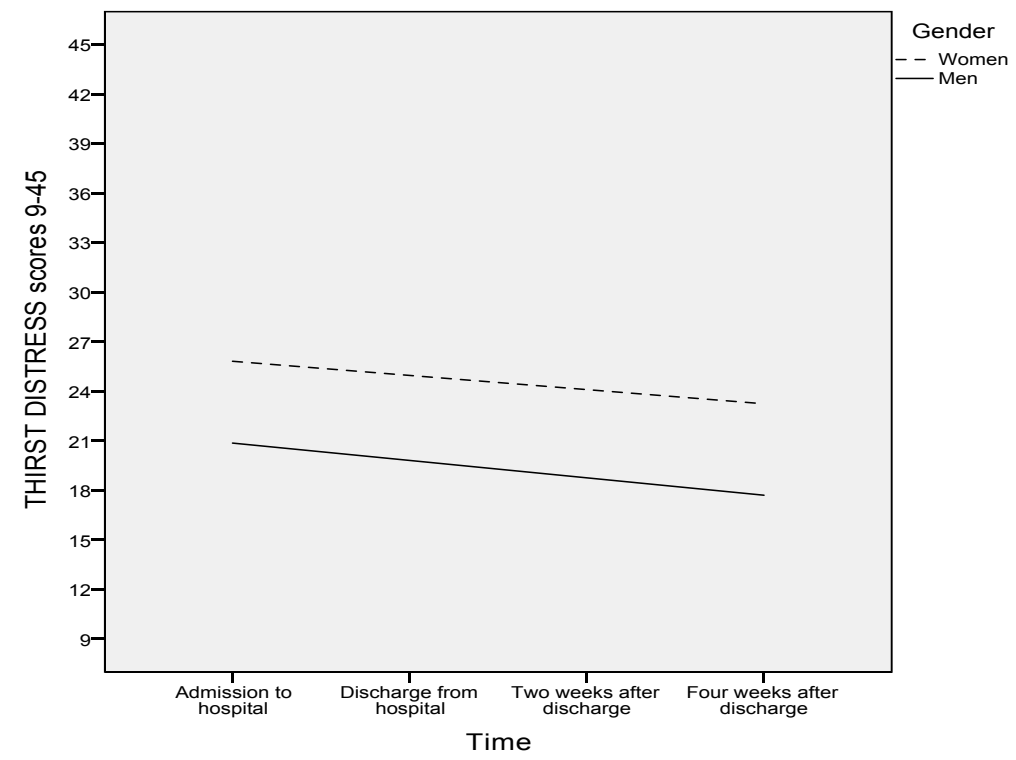

Figure 8. Thirst distress trajectories in women and men (IV).

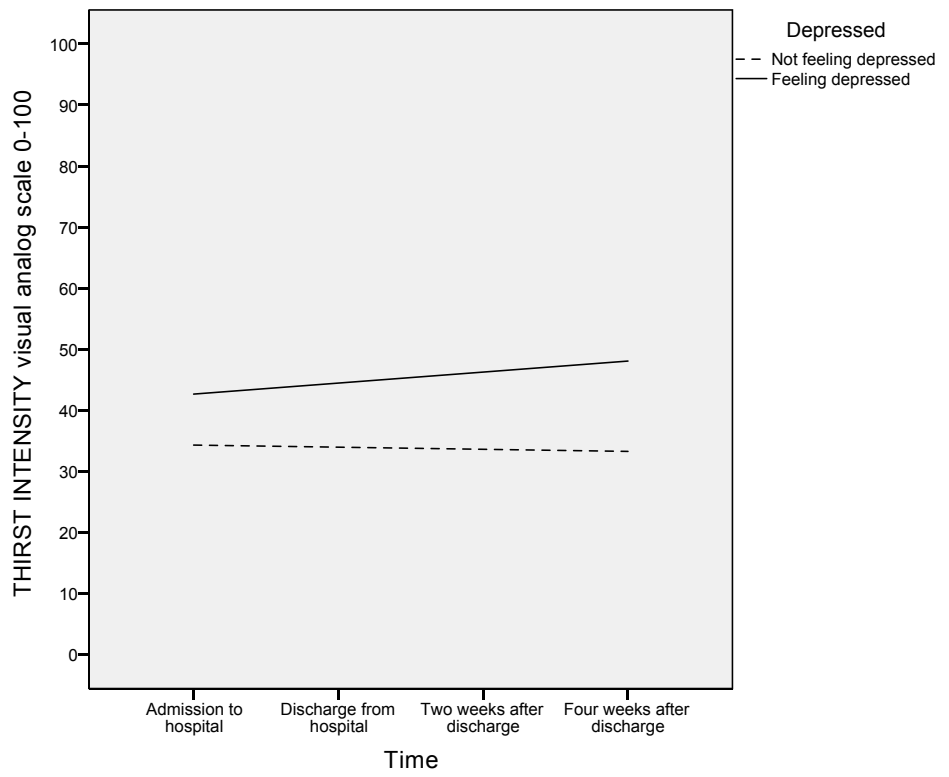

Figure 9. Thirst intensity trajectories for patients feeling depressed and patients who did not feel depressed (IV). 


\section{Thirst intensity}

Thirst intensity was highest in patients admitted to hospital due to decompensated HF at baseline (VAS median $75 \mathrm{~mm}$ ) (I) and lowest in patients at an outpatient clinic (median $14 \mathrm{~mm}$ ) (III) (Figure 10). Thirst intensity was moderate in patients with decompensated HF admitted to hospital and followed at discharge, two and four weeks after discharge (IV) (Figure 10).

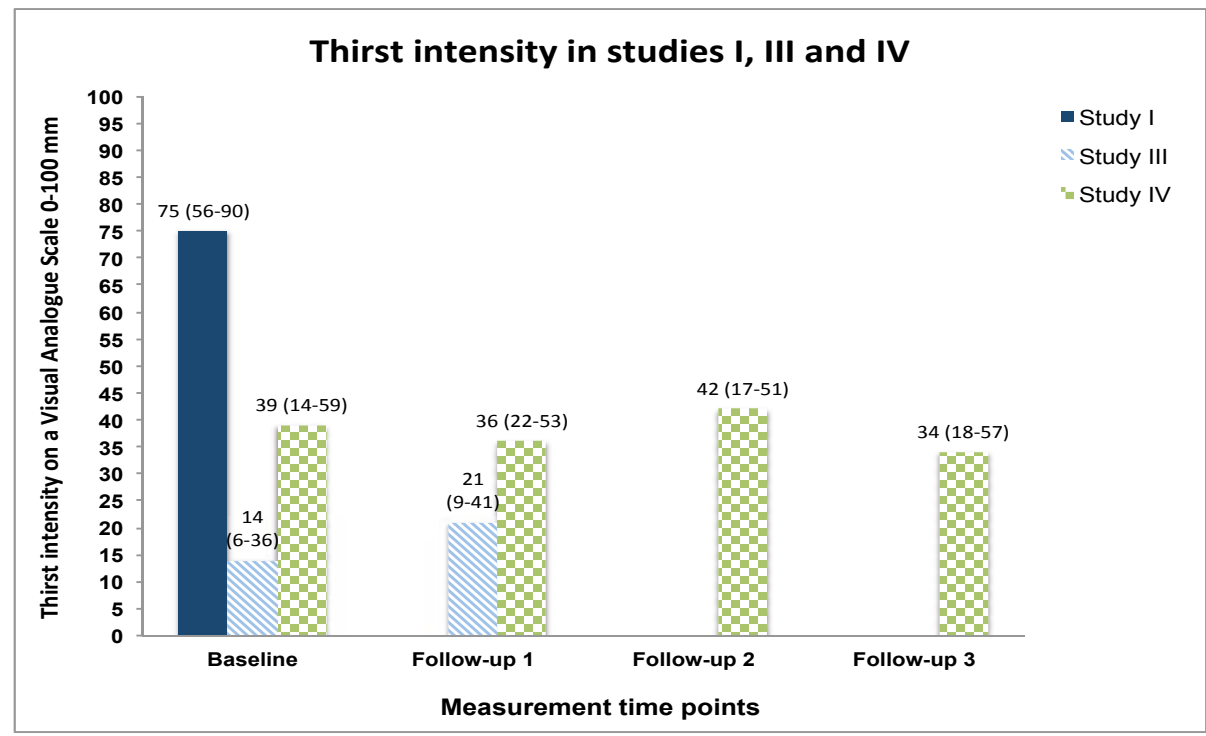

Figure 10. Thirst intensity scores (median and inter-quartile range) in patients with HF admitted to hospital (I, IV) and followed at discharge, two and four weeks after discharge (IV) and in patients at an outpatient HF clinic at baseline and the study end (III).

Thirst intensity was significantly higher in patients admitted to hospital with decompensated HF compared to patients without HF but due to other illness (median 75 [IQR 56-90] vs. 25 [11-40] mm; $P<0.0001$ ) (I) (Figure 11). Patients in the group with high thirst intensity at the outpatient clinic did not have higher thirst intensity at the baseline compared to those with low thirst intensity (18 [733] vs. 10 [5-45] mm; $P=0.61$ ) (III). After HF medication uptitration at the study end, thirst intensity was significantly higher in the group with high thirst intensity 
compared to the group with low thirst intensity (39 [30-61] vs. 9 [5-14] mm; $P<0.001)$.

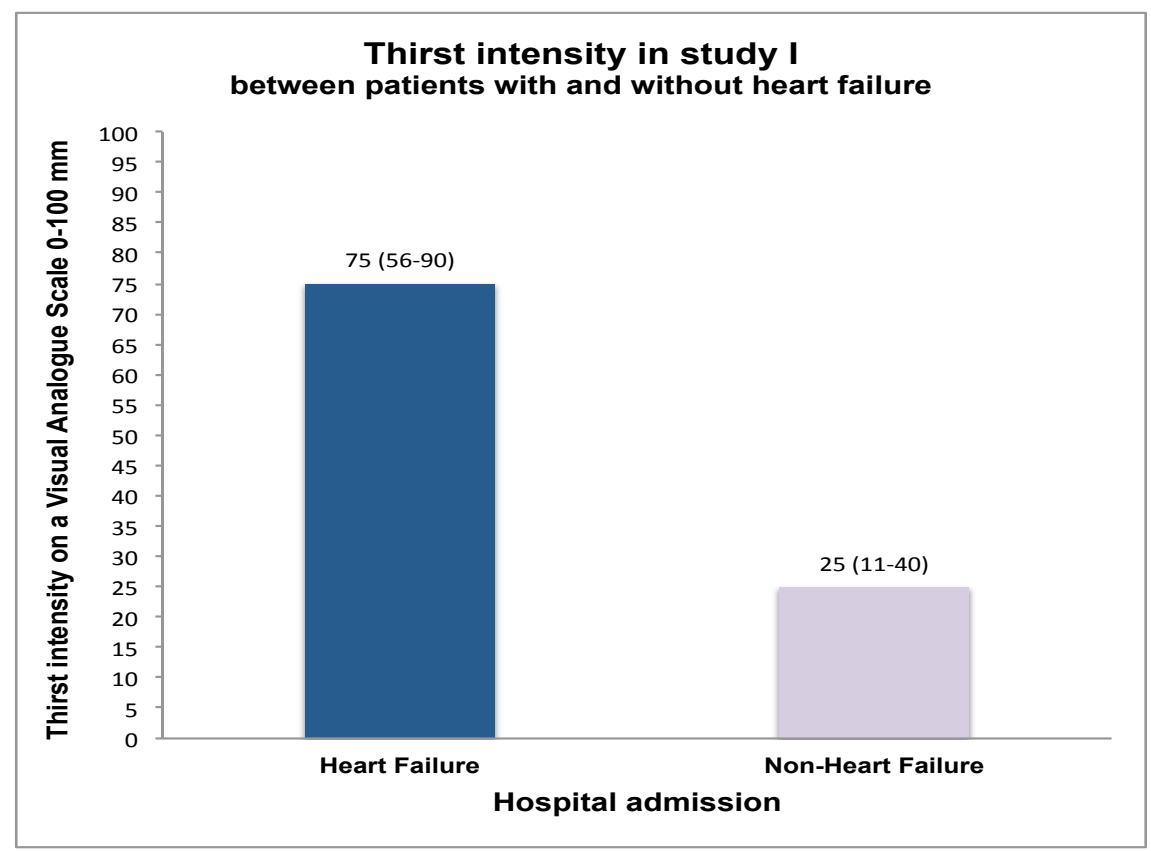

Figure 11. Thirst intensity in patients with HF compared with patients without HF at hospital admission $(P<0.0001$, Mann-Whitney U-test $)(\mathrm{I})$.

Thirst intensity increased in $67 \%$ of the patients during uptitration of HF medication and decreased in 33\% of the patients (III). The change in thirst intensity was significantly different between those who increased and decreased (median IQR, +13 [+5 to 27] mm vs. $-26[-40$ to -5$] \mathrm{mm} ; P<0.001)$.

For patients in the high thirst intensity group, the change in thirst intensity was significantly higher compared to patients in the low thirst intensity group $(+18[+9$ to 36$]$ vs. $-3[-33$ to 5$] \mathrm{mm} ; \mathrm{p}<0.001)$ (III). 


\section{Thirst distress}

Moderate to severe thirst distress was reported by $63 \%$ of patients with $\mathrm{HF}$ admitted to hospital (IV) and by $41 \%$ of patients at an outpatient clinic (III). During HF medication uptitration, more patients in the high thirst intensity group increased moderate to severe thirst distress $(55 \%$ to $61 \%)$, while in the low thirst intensity group more patients decreased moderate to severe thirst distress $(30 \%$ to $15 \%)$.

Thirst distress scores were slightly higher in patients admitted to hospital (IV) compared to patients at an outpatient clinic (III) (Figure 12). Patients in the group with high thirst intensity did not have higher thirst distress at the baseline compared to those with low thirst intensity $(21$ [12-23] vs. 13 [10-21] mm; $P=0.08$ ) (III). At the end of the study, thirst distress was significantly higher in patients with high thirst intensity compared to those with low thirst intensity (21 [14-25] vs. 12 [10-18] mm; $P<0.001)$.

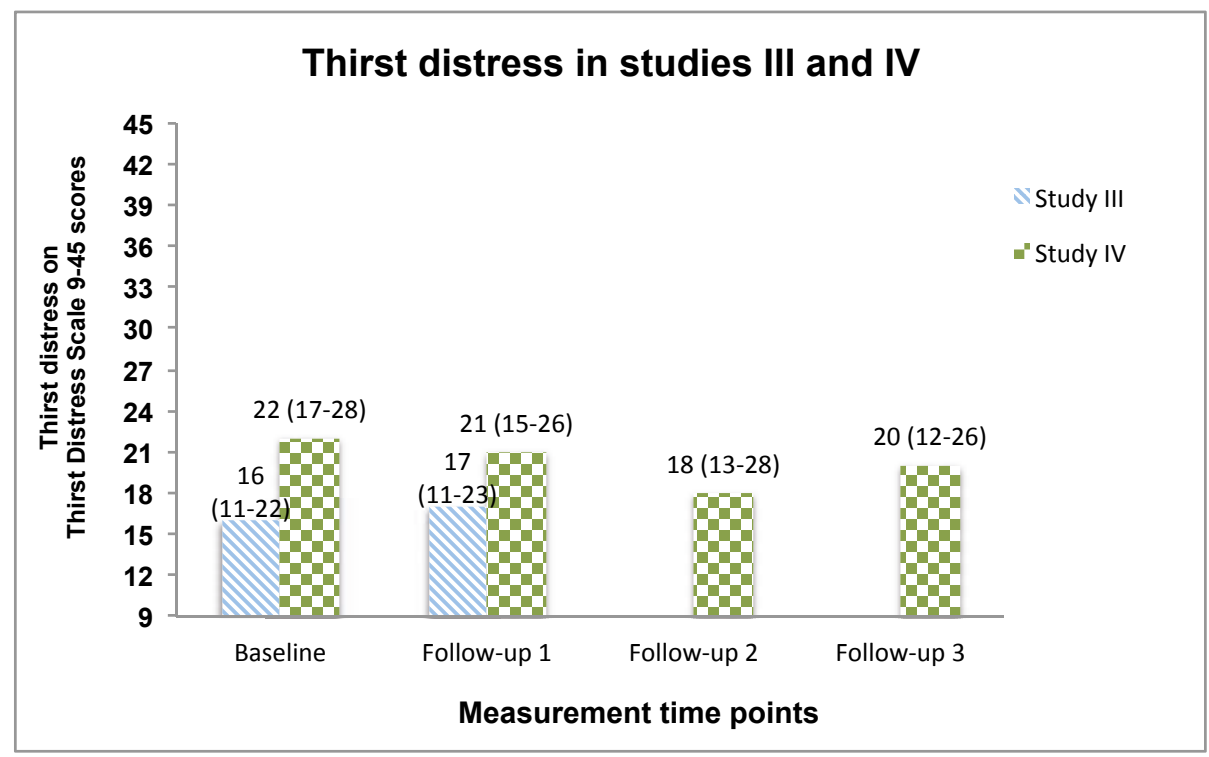

Figure 12. Thirst distress scores (median and inter-quartile range) in patients with HF at an outpatient clinic at baseline and the study end (III) and in patients at hospital admission, at discharge, two and four weeks after discharge (IV). 


\section{Thirst quality}

Thirst was reported most often as bothersome and with a feeling of dry mouth (III, IV) (Table 9). Thirst could be a bothering experience every day and for some patients, the mouth could feel like sandpaper. Feeling thirst was associated with being uncomfortable. Some patients felt that thirst was insurmountable (Table 9). Patients admitted to hospital (IV) felt more discomfort with thirst than patients at the outpatient clinic (III).

Table 9. Descriptions of how thirst feels like and its associated discomfort at the baseline and end of study (III, IV)*

\begin{tabular}{lcc|cc}
\hline & \multicolumn{2}{c}{ Study III } & \multicolumn{2}{c}{ Study IV } \\
Item & Start & End & Start & End \\
& $\mathrm{n}=69$ & $\mathrm{n}=66$ & $\mathrm{n}=30$ & $\mathrm{n}=25$ \\
\hline My thirst bothers me a lot & $19(28 \%)$ & $19(29 \%)$ & $15(50 \%)$ & $12(48 \%)$ \\
My thirst bothers me daily & $16(23 \%)$ & $16(24 \%)$ & $14(47 \%)$ & $14(56 \%)$ \\
I am very uncomfortable when I am thirsty & $18(26 \%)$ & $14(21 \%)$ & $15(50 \%)$ & $10(40 \%)$ \\
My mouth feels like sandpaper when I am & $22(32 \%)$ & $22(33 \%)$ & $18(60 \%)$ & $8(32 \%)$ \\
thirsty & & & & \\
My mouth feels dry when I am thirsty & $36(52 \%)$ & $23(35 \%)$ & $26(87 \%)$ & $18(72 \%)$ \\
My saliva is very thick when I am thirsty & $19(28 \%)$ & $15(23 \%)$ & $12(40 \%)$ & $7(28 \%)$ \\
When I drink less water, my thirst gets worse & $25(36 \%)$ & $20(30 \%)$ & $14(46 \%)$ & $10(40 \%)$ \\
I am so thirsty I could drink water uncontrol- & $18(26 \%)$ & $15(23 \%)$ & $10(33 \%)$ & $6(24 \%)$ \\
lably & & & & \\
My thirst feels insurmountable & $10(14 \%)$ & $8(12 \%)$ & $5(17 \%)$ & $4(16 \%)$ \\
\hline
\end{tabular}

* Not published data; Values are presented as number of patients (\%).

Patients in the high thirst intensity group (III) experienced more discomfort with thirst after HF medication uptitration (Table 10) (III). They more often felt that thirst was bothersome, and if they were drinking less water, their thirst increased. Patients with high thirst intensity were also more often feeling that thirst was 
bothersome every day, and they felt that they could drink water uncontrollably because of thirst.

Table 10. Descriptions of what thirst feels like and its associated discomfort for patients with low and high thirst intensity at the baseline and end of study (III).*

\begin{tabular}{lcc|cc}
\hline & \multicolumn{2}{c}{ Low thirst intensity } & \multicolumn{2}{c}{ High thirst intensity } \\
Item & Start & End & Start & End \\
& $\mathrm{n}=33$ & $\mathrm{n}=33$ & $\mathrm{n}=33$ & $\mathrm{n}=33$ \\
\hline My thirst bothers me a lot & $9(27 \%)$ & $4(12 \%)$ & $9(27 \%)$ & $15(45 \%)$ \\
My thirst bothers me daily & $7(21 \%)$ & $4(12 \%)$ & $8(24 \%)$ & $12(36 \%)$ \\
I am very uncomfortable when I am thirsty & $8(24 \%)$ & $3(9 \%)$ & $9(27 \%)$ & $11(33 \%)$ \\
My mouth feels like sandpaper when I am & $9(27 \%)$ & $9(27 \%)$ & $12(36 \%)$ & $13(39 \%)$ \\
thirsty & & & & \\
My mouth feels dry when I am thirsty & $17(52 \%)$ & $8(24 \%)$ & $18(54 \%)$ & $15(45 \%)$ \\
My saliva is very thick when I am thirsty & $7(21 \%)$ & $6(18 \%)$ & $11(33 \%)$ & $9(27 \%)$ \\
When I drink less water, my thirst gets worse & $9(27 \%)$ & $5(15 \%)$ & $15(45 \%)$ & $15(45 \%)$ \\
I am so thirsty I could drink water uncontrol- & $6(18 \%)$ & $4(12 \%)$ & $11(33 \%)$ & $11(33 \%)$ \\
lably & & & & \\
My thirst feels insurmountable & $5(15 \%)$ & $2(6 \%)$ & $5(12 \%)$ & $6(18 \%)$ \\
\hline
\end{tabular}

* Not published data. Values are presented as number of patients (\%).

\section{Factors related to thirst}

Several factors were found to be related to thirst in the different studies. Summarizing, patients with persistent thirst were younger in age, more often men, had higher BMI, serum urea and more depressive symptoms, and they had more HF symptoms and prescribed diuretics (II) (Table 11). Patients with high thirst intensity were more often in NYHA class III-IV, had higher NT-proBNP and urea, and they were more often prescribed diuretics $\geq 40 \mathrm{mg}$ /day and a fluid restriction (III) (Table 11). 


\section{Situational factors}

Fluid restriction was more often prescribed in patients with high thirst intensity (Table 11). Patients with HF who were measured in the morning, before they had taken their morning medication and eaten breakfast, had a median thirst intensity of $75 \mathrm{~mm}$ (IQR 56-90), compared to patients who were measured at daytime who had a median thirst intensity of $14 \mathrm{~mm}$ (6-36) (III) and $39 \mathrm{~mm}$ (14-59) (IV) at the study baseline.

The mean scores for self-care behaviour were $61 \pm 22$ (III) and $63 \pm 20$ (IV). No difference was found in HF self-care behaviour between patients with high thirst intensity and patients with low thirst intensity (III) (Table 11).

\section{Physiological factors}

The median plasma urea concentration of patients with HF was higher (reference interval 3-8 $\mathrm{mmol} / \mathrm{L}$ ) in those with persistent thirst (II) and high thirst intensity (III), which gives an indication of the presence of dehydration and increased neurohormonal activity (Table 11). Plasma urea was significantly higher at study baseline and at the end in patients with high thirst intensity compared to patients with low thirst intensity (median 8 [IQR 6-11] mmol/L vs. 7 [5-8]; $P \leq 0.05$, and 9 [7-11] vs. 7 [5-8]; $P \leq 0.01$ ) (III) (Table 11). Serum osmolality of the patients in the study was increased indicating dehydration, but no association was found to thirst (III, IV). Urine colour indicated the presence of dehydration (urine colour $\geq 3$ ) in $61 \%$ of patients with HF and in $64 \%$ of patients without HF (I). No association was found between higher thirst intensity and darker urine colour. 
Table 11. Comparisons of factors between patients with and without persistent thirst (II) and between patients with high and low thirst intensity (III).

\begin{tabular}{|c|c|c|c|c|}
\hline \multirow[b]{2}{*}{ Variable } & \multicolumn{2}{|c|}{$\begin{array}{c}\text { Study II } \\
\text { Persistent thirst }\end{array}$} & \multicolumn{2}{|c|}{$\begin{array}{c}\text { Study III } \\
\text { High thirst intensity }\end{array}$} \\
\hline & $\begin{array}{c}\text { Yes } \\
(\mathrm{n}=121)\end{array}$ & $\begin{array}{c}\text { No } \\
(\mathrm{n}=528)\end{array}$ & $\begin{array}{c}\text { Yes } \\
(\mathrm{n}=33)\end{array}$ & $\begin{array}{c}\text { No } \\
(\mathrm{n}=33)\end{array}$ \\
\hline Age & $64 \pm 12$ & $70 \pm 11 *$ & $74 \pm 7$ & $72 \pm 8$ \\
\hline Men, $\%$ & 75 & $59 *$ & 85 & 82 \\
\hline Cohabiting, $\%$ & 68 & 61 & 64 & 49 \\
\hline Systolic BP, mm Hg & $119 \pm 22$ & $119 \pm 21$ & $117 \pm 19$ & $125 \pm 18$ \\
\hline Diastoloc BP, mm Hg & $71 \pm 12$ & $69 \pm 11$ & $73 \pm 12$ & $72 \pm 11$ \\
\hline LVEF, \% & $33 \pm 14$ & $33 \pm 14$ & $32 \pm 10$ & $33 \pm 9$ \\
\hline NYHA class III-IV, \% & 45 & 44 & 49 & $21 *$ \\
\hline $\mathrm{BMI}, \mathrm{kg} / \mathrm{m}^{2}$ & $29 \pm 6$ & $27 \pm 5^{*}$ & $27 \pm 5$ & $27 \pm 5$ \\
\hline P/NT-proBNP, ng/L & $\begin{array}{c}2073 \\
(992-4456)\end{array}$ & $\begin{array}{c}2171 \\
(1129-4252)\end{array}$ & $\begin{array}{c}2300 \\
(787-4310)\end{array}$ & $\begin{array}{c}1260 \\
(349-2860)^{*}\end{array}$ \\
\hline $\mathrm{P} /$ Aldosterone, $\mathrm{pmol} / \mathrm{L}$ & - & - & $258(107-402)$ & $164(75-304)$ \\
\hline $\mathrm{P} /$ Urea, $\mathrm{mmol} / \mathrm{L}$ & $11(8-15)$ & $10(8-14)^{*}$ & $9(7-11)$ & $7(5-8)^{*}$ \\
\hline $\mathrm{P} /$ Sodium, mmol/L & $139 \pm 4$ & $139 \pm 4$ & $139 \pm 2$ & $139 \pm 2$ \\
\hline S/Osmolality, mosmol/kg & - & - & $301 \pm 6$ & $298 \pm 5$ \\
\hline $\mathrm{S} /$ Creatinine, $\mu \mathrm{mol} / \mathrm{L}$ & $121 \pm 38$ & $116 \pm 45$ & $111 \pm 27$ & $96 \pm 29^{*}$ \\
\hline $\mathrm{Sa} /$ Cortisol, $\mathrm{nmol} / \mathrm{L}$ & - & - & $26(19-37)$ & $23(17-32)$ \\
\hline Diuretics, \% & 99 & $95^{*}$ & 70 & 58 \\
\hline Diuretics $\geq 40 \mathrm{mg} /$ day, $\%$ & - & - & 55 & $30 *$ \\
\hline $\mathrm{ACE}, \%$ & 77 & 76 & 67 & 79 \\
\hline $\mathrm{ARB}, \%$ & 12 & 13 & 27 & 21 \\
\hline MRA, $\%$ & 62 & 53 & 21 & 18 \\
\hline Antidepressants, $\%$ & 10 & 6 & 3 & 0 \\
\hline Fluid restriction, $\%$ & 62 & 67 & 64 & $21 *$ \\
\hline $\begin{array}{l}\text { HF symptoms, number of } \\
0-10\end{array}$ & $4 \pm 3$ & $3 \pm 2 *$ & - & - \\
\hline $\begin{array}{l}\text { Depressive symptoms } \\
\text { CES-D scale score } 0-60\end{array}$ & $15(8-25)$ & $12(6-19)^{*}$ & - & - \\
\hline Feeling anxious, $\%$ & - & - & 42 & 24 \\
\hline Feeling depressed, $\%$ & - & - & 39 & 24 \\
\hline $\begin{array}{l}\text { HF Self-Care behaviour } \\
\text { Score } 0-100\end{array}$ & - & - & $58 \pm 14$ & $64 \pm 26$ \\
\hline
\end{tabular}

BP, blood pressure; LVEF, left ventricular ejection fraction; BMI, body mass index; NYHA, New York Heart Association functional class; NT-proBNP, N-terminal of the prohormone brain natriuretic peptide; P, plasma; S, serum; Sa, saliva; ACE, Angiotensin-converting enzyme inhibitor; ARB, Angiotensin II receptor blocker; MRA, Mineralocorticoid receptor antagonist. Between group comparisons: ${ }^{*} \mathrm{P}<0.05$. Values are presented as mean $\pm \mathrm{SD}$, median (IQR), or \% . 
Patients with persistent thirst often had more diuretics prescribed (II) and diuretic doses of $\geq 40 \mathrm{mg} /$ day were more often prescribed in patients with high thirst intensity compared to patients with low thirst intensity (55 vs. 30\%; $P$ $<0.05$ ) (III) (Table 11).

NYHA class III-IV was present in more patients with high thirst intensity compared to patients with low thirst intensity at the study end (49\% [n=16] vs. $21 \%[\mathrm{n}=7] ; P \leq 0.05$ ) (III) (Table 11). More patients with high thirst intensity increased in NYHA class compared to those with low thirst intensity during optimization of HF medication ( $\mathrm{n}=4$ vs. $0 ; P<0.04)$ (III).

In patients with high thirst intensity, the concentration of NT-proBNP was significantly higher at baseline and at the study end compared to the patients with low thirst intensity (median 2230 [IQR 1175-5015] mmol/L vs. 1580 [477-2790]; $P \leq 0.05$, and 2300 [787-4310] vs. 1260 [349-2860]; $P \leq 0.05)$ (III) (Table 11).

In study II, more men had persistent thirst (Table 11).

\section{Psychological factors}

Feeling depressed and feeling anxious was reported in more patients with higher thirst intensity compared to patients with lower thirst intensity (III). Higher depressive symptoms scores were found in patients with persistent thirst compared to those with no persistent thirst (14.5 vs. 12.0 scores; $P=0.02$ ) (II) (Table 11).

Feeling depressed and feeling anxious was reported in more patients with high thirst intensity at the end of the study compared to baseline ( $\mathrm{n}=13$ vs. 8 , $P=0.23$; and $\mathrm{n}=14$ vs. $6, P=0.06$ ) (III) (Table 11 ). Patients with HF and anxiety/depression $(n=15)$ had higher median thirst intensity compared to those with no anxiety/depression ( $\mathrm{n}=8)(85$ vs. $57 \mathrm{~mm} ; P<0.04)(\mathrm{I})$.

Stress measured with saliva cortisol increased from baseline to study end in patients with high thirst intensity (median 20 [IQR 12-26] nmol/L to 26 [19-37]; $P=0.001$ ), while cortisol remained unchanged in patients with low thirst intensity (25 [19-34] nmol/L to 23 [17-32]; $P=0.58)$. 


\section{Independent factors for thirst}

When analysing age, gender, living alone or taking diuretics together with the presence and absence of HF, no significant factors of thirst were found (two-, and three-way ANOVA) (I).

Logistic regression analyses were conducted to identify the factors associated with persistent thirst (II) and with high thirst intensity (III). Following variables were included in the logistic regressions: age, gender, BMI, serum urea, depressive symptoms score, prescribed diuretics, antidepressive medication, cohabiting, MRA, and diastolic blood pressure (II); and fluid restriction, plasma urea, NYHA class III-IV, thirst intensity at baseline, prescribed diuretic $40 \mathrm{mg} /$ day, plasma creatinine, and NT-proBNP (III).

In the logistic regression analysis in study II, higher BMI (odds ratio [OR] 1.06; $P \leq 0.01$ ), higher plasma urea (OR $1.05 ; P \leq 0.05)$, and more HF symptoms (OR $1.14 ; P \leq 0.05)$ were independently associated with persistent thirst (Table 12). Older patients (OR $0.96 ; P \leq 0.01)$ and women (OR $0.43 ; P \leq 0.01$ ) had a decreased risk for persistent thirst (II). In study III, fluid restriction (OR 6.25; $P$ $\leq 0.01)$ and higher plasma urea (OR $1.33 ; P \leq 0.05)$ were independently associated with high thirst intensity (III) (Table 12).

Table 12. Independent variables for persistent thirst and high thirst intensity (III, IV).

\begin{tabular}{llcc}
\hline Thirst & Variable & Odds Ratio & 95\% Confidence Interval \\
\hline Persistent thirst & & & \\
$\mathrm{n}=649$ (II) & & 0.96 & $0.94-0.98^{* *}$ \\
& Age, years & 0.43 & $0.23-0.74^{* *}$ \\
& Sex, female & 1.06 & $1.02-1.12^{* *}$ \\
& BMI, $\mathrm{kg} / \mathrm{m}^{2}$ & 1.05 & $1.01-1.10^{*}$ \\
& Serum urea, mmol/L & 1.14 & $1.01-1.26^{*}$ \\
High thirst intensity & HF symptoms, number & & \\
$\mathrm{n}=66$ (III) & & 6.25 & $1.90-20.5^{* *}$ \\
& Fluid restriction, no/yes & 1.33 & $1.07-1.65^{*}$ \\
\hline
\end{tabular}

BMI, body mass index; HF, heart failure.

** $P \leq 0.01 ; * P \leq 0.05$ 


\section{DISCUSSION}

The aim of this thesis was to describe the thirst experience of patients with HF and describe the relationship of thirst with physiological, psychological and situational factors. The goal was to contribute to the improvement of the care by identifying needs and possible approaches to prevent and relieve thirst in patients with HF.

The main results in this thesis is that one in five patients with HF experience thirst, and hospitalized patients with HF have higher thirst intensity compared to patients with HF at an outpatient clinic. Moderate to severe thirst distress was experienced by $63 \%$ of patients with HF admitted to the hospital, and by $41 \%$ of patients referred to an outpatient clinic. Other important findings were that patients who were admitted to the hospital with a high thirst distress continued to have a high thirst distress over time, and once patients were thirsty, they were more likely to become thirsty again.

This thesis is the first to describe the prevalence of thirst in patients with HF in a systematic way. A previous study showed that $9 \%$ of patients with $\mathrm{HF}$ suffered from thirst in the last six months of life. ${ }^{4}$ However, the results were retrieved by examining medical records and the documentation in the records was generally brief. Therefore, the estimated prevalence of thirst may be too low. In an intensive care unit, $40 \%$ of the patients had thirst ${ }^{35}$ and for patients with cancer in the end of life, thirst was prevalent in $62 \%{ }^{31}$ As stated above, this thesis found that $20 \%$ of stable HF patients had thirst. The prevalence of thirst in the end of life is less known, but patients living with severe HF in palliative care are described to suffer from thirst. ${ }^{6}$

Trajectories on the thirst presence showed that most of the patients did not have thirst, but for many of the patients' thirst came and went, and for some patients' thirst was present at every visit. The importance of time was highlighted for the findings on patients who once got thirsty and were more likely to become 
thirsty again. This highlights the value of asking patients regularly about whether they have thirst, as the risk of experiencing thirst in future increases when the patient once report having thirst. This shows that time can be an important component to include in the interpretation with thirst. The impact of time on the meaning the patient attaches to thirst is important, as it can affect the patients' evaluation of the thirst experience, and emotional response to it. ${ }^{37}$

Persistent thirst was present in $19 \%$ of patients with stable HF and was defined as having thirst at $\geq 2$ of 4 occasions during the 18 -month study period. It could be argued that the definition is not restrictive enough, but there was no other previous definition for persistent thirst. Including persistent thirst in the thirst experience adds the perspective of ongoing thirst that does not disappear completely. Previous research shows that patients who experience other symptoms over time, such as depressive symptoms and severe fatigue, have a worse prognosis with rehospitalisation and increased mortality risk. ${ }^{21,23,115,116}$

The highest thirst intensity levels were found in patients who were hospitalized for HF deterioration and the lowest levels in patients referred for HF medication uptitration at an outpatient clinic. Previous studies with both stable and decompensated HF patients show moderate levels of thirst intensity. ${ }^{84-87}$ Thirst intensity trajectories did not change over time, except for those patients who were admitted to hospital with high and low thirst intensity levels. Similar thirst intensity changes were seen in a previous study examining the effects of fluid restriction. ${ }^{39}$ Thirst intensity quantifies the strength of thirst and is the dimension of thirst that is most often used in both research and clinic. ${ }^{37,38,43,95}$ The different intensity levels in this thesis may be explained by factors that can have an influence on thirst intensity and are discussed later. Essentially, the intensity is the sensation that arises within the patient resulting from dehydration and makes patients search for water to drink. ${ }^{3,47}$ Thirst intensity is a vital sensation for survival, as death can occur within a week if a person does not drink water. ${ }^{3,48}$ The strength of the intensity is perceived depends on cerebral blood flow and the sensitivity of receptors responding to changes in central blood volume. ${ }^{59}$ Different intensity levels can also be due to individual perceptions of thirst intensity. ${ }^{11,117}$ 
Previous research shows that the perception of symptoms can be influenced by the personality, cognitive capacity, culture, and impaired symptom recognition. ${ }^{83}$, 117,118

In total $63 \%$ of patients who were admitted to hospital with worsening of HF symptoms experienced moderate to severe thirst distress. Patients with high thirst distress at hospital admission continued to have high thirst distress over time. Thirst distress is the individual experience of what bothersome and troubling thirst feels like. ${ }^{37,43}$ The distress dimension has also been described as the emotional burden that is experienced from a symptom. ${ }^{119}$ The degree of distress that is experiences from a symptom, is generally associated with the level of intensity. ${ }^{37}$ These two dimensions can also differ from each other due to different influencing factors. Thirst distress might be affected by the attention the patient directs to the thirst. For example patients with HF who restrict their fluid intake can go the whole day thinking that they are thirsty. ${ }^{10}$ Symptom management strategies to decrease distress have focused on diverting attention from the symptom. ${ }^{37}$ It is also important to consider the influence on the degree of thirst distress that can be the meaning that the patient assigns to thirst. The meaning assigned to thirst by the patient can be important to consider as the dimension of distress might have emotional consequences for patients, such as described by HF patients as suffering and struggling from thirst. ${ }^{6}$

The quality dimension of thirst was used to describe what thirst felt like and can provide knowledge on what it feels like to be thirsty. ${ }^{37}$ Different symptoms have their own characteristics, and therefore the descriptors for each symptom are highly specific. The quality dimension for thirst therefore describes the unique characteristics for thirst. Many of the patients felt that they had a dry mouth when they were thirsty. Dry mouth has been reported as one of the most prevalent symptoms in patients with HF. ${ }^{71,73,74}$ Not surprisingly, thirst has been defined as a sensation of dryness in the mouth. ${ }^{25}$ Considering the relation between dry mouth and dehydration ${ }^{50}$ and thirst and dehydration ${ }^{3,47}$ it seems logical that these two sensations are associated with each other. About half of the patients admitted to hospital were bothered by thirst every day, and their thirst 
could be very troublesome. Patients who had high thirst intensity were even more often bothered by thirst and also felt that their thirst got worse when they drank less water. In previous studies, thirst was described as enormously annoying ${ }^{7}$ and patients with severe HF had an irresistible need to drink. ${ }^{6}$ Thirst can be of great concern for patients with HF, and it can be difficult for them to find anything that relieves their thirst for more than a short time. ${ }^{6,7}$

This thesis also examined the situational, physiological and psychological factors that could affect the thirst experience. ${ }^{37}$ The main findings were within the situational and physiological factors. Thirst was associated with having a fluid restriction and higher concentration of plasma urea. Having a fluid restriction contributed to increased thirst distress over time. Other interesting findings were that patients with thirst had more severe HF, increased stress, and more depressive symptoms.

Significant relationship between fluid restriction and high thirst intensity, independent of HF severity or HF medication were found. The results are further strengthened by the finding that having fluid restriction contributed to increased thirst distress over time. Fluid restriction has been stated to be associated with thirst by patients with HF in previous studies. ${ }^{6,7,10}$ Guidelines recommend fluid restriction to be reasonable to patients who have advanced $\mathrm{HF}$ and are in need of relieve of HF symptoms and congestion. ${ }^{12,120}$ Fluid restriction can be part of the HF patients' self-care behaviour. ${ }^{12,76}$ Patients might continue having a fluid restriction, even when they no longer require such a restriction. This thesis shows that having a fluid restriction is strongly associated with increased thirst and therefore, nurses should ask patients with thirst if they have a fluid restriction. If so, they should investigate the need of the fluid restriction for the patient.

For those patients who truly need a fluid restriction, nurses should consider that patients' ability to succeed in restricting fluids when they have increased thirst might be dependent on factors such as motivation, habits and support from others. ${ }^{18}$ To succeed in restricting their fluids, patients with increased thirst may need coaching by exchanging ideas on distributing fluid intake evenly throughout the day ${ }^{86}$ and using ice cubes or peppermints. ${ }^{10}$ A saliva substitute or chewing 
gum might also be tested to increase thirst. ${ }^{29} \mathrm{~A}$ weight-based fluid restriction (30 $\mathrm{ml} / \mathrm{kg} /$ day) could also be tested, as it may cause less thirst. ${ }^{84,85}$ The findings in this thesis also showed that thirst distress continued over time in patients with HF with a fluid restriction, which indicates the need to evaluate the effects of interventions on thirst regularly.

Of the physiological factors that were studied in this thesis, the plasma urea was found to be associated with high thirst intensity and persistent thirst. Urea can be a marker of dehydration, as it increases in blood when body water is in short supply. ${ }^{3}$ Urea has also been described to be a marker of neurohormonal activation in patients with HF. ${ }^{62,121,122}$ The neurohormonal activation cause vasoconstriction of arteriole, which leads to a reduction in renal perfusion. This action increases water and urea reabsorption, which results in an increased concentration of urea. ${ }^{3}$ Even mild to moderate elevations of plasma urea can predict rehospitalisation, adverse effects of diuretics and mortality. ${ }^{62,121,122}$ Although patients with HF did not have very high levels of urea, the increase of urea seen in this thesis may reflect a higher neurohormonal activation in those HF patients with increased thirst. Patients with more severe HF, reflected by higher NTproBNP and more patients classified as NYHA III and IV, was associated with higher thirst intensity.

The only pharmacological treatment that was found to be associated with increased thirst was the use of diuretics ( $\geq 40 \mathrm{mg} /$ day). Diuretics are used to relieve symptoms in patients with HF. They increase the excretion of body water ${ }^{12}$ and might therefore cause dehydration, which is a known cause for thirst. ${ }^{3}$ The serum osmolality was used to detect dehydration, which was present in many of the patients.

Of the psychological factors studied it was found that patients with HF with depressive symptoms had persistent thirst. The results also showed that more patients who increased their thirst intensity also felt more depressed and anxious. Previous studies have found an association between a larger number of symptoms in patients with HF and depression. ${ }^{73}$ The Theory of Unpleasant Symptoms also asserts that symptoms can result from or be aggravated by depression. ${ }^{43}$ The 
association between depression and thirst can be interpreted in different ways. Depression can lead to increased sensitivity and reporting of symptoms. ${ }^{123}$ Patients with HF and depression may therefore experience the thirst more intense and distressing because of the increased sensitivity that can occur with a depression. It has also been suggested that it could be the other way around, that the symptom distress might lead to depression. ${ }^{73}$ Few of the patients in the studies in this thesis had a diagnosis of depression. The prevalence of unrecognized depression in patients with HF can be high, as depressive symptoms have been found in between $30 \%$ and $70 \%$ of patients with $\mathrm{HF}^{72,75}$

The findings also showed that patients who increased their thirst intensity also increased, stress measured with cortisol. The association between stress and thirst might be caused by the high sympathetic activity in HF as well as the stressful life situations HF patients are coping with. ${ }^{6,7,10}$ Previous research has also shown that stress sensitivity, measured with cortisol, is increased in patients with depression. ${ }^{124}$

Surprisingly, this thesis found that thirst intensity increased in $67 \%$ of the patients during uptitration of HF medication. The expectation was that optimization of HF medication would lower thirst. The goal of optimizing of HF medication is to interrupt the neurohormonal activation and decrease HF symptoms. ${ }^{12}$ However, only a few patients improved their NYHA class and NT-proBNP during the up titration. The reason for the increase in thirst could also be explained by the high number of patients having a fluid restriction.

An additional finding in this thesis was that men had more often persistent thirst, but women had higher thirst distress over time. In healthy persons, thirst has not been reported to differ between men and women. ${ }^{27}$ Also, younger age was associated with persistent thirst, which is consistent with studies showing diminished thirst in aging. ${ }^{57-59}$ There was no relationship between the HF selfcare behaviour and thirst. This is probably due to the fact that HF self-care behavior includes several different behaviours, in addition to fluid restriction, which are not related to thirst. 


\section{Reflections on the theoretical framework}

The Theory of Unpleasant Symptoms used in this thesis has a practical adequacy. It is applicable in both research and practice, and gives a more accurate representation of the complexity of the symptom experience. It focuses on relevant concerns within the nursing research and practice, namely the unpleasant symptoms that can be experienced in many patients.

The theory has a multidimensional perspective, including different dimensions of the symptom, possible factors associated with the symptom as well as an outcome of the symptom experience, which strengthens the description of the symptom. As such, the theory aligns with holistic nursing, meaning that it focuses on the whole patient rather than just a part of the patient. ${ }^{125}$ This also means that the patient is viewed as a person. Holistic nursing care is patient focused to provide individualised care. The Theory of Unpleasant Symptoms lacks, though, a clear description on the worldview and the paradigm.

The Theory of Unpleasant Symptoms has one major limitation, as experienced working with it in this thesis. The theory lacks a component that include a temporal dimension of a symptom..$^{91}$ The temporal aspect of a symptom is considered as important, as it is known that symptoms may change over time. It has been suggested by researchers, that statistical approaches must be considered, prior the inclusion of a temporal aspect of the symptom in symptom theories. ${ }^{91}$ For this thesis, growth modelling was used to display thirst trajectories in order to find out if there were any changes or differences in the trajectories of the intensity and the distress. A strength in this thesis is the use of trajectories that are displayed by the presence of thirst, the thirst intensity and thirst distress.

The theory might also lack an additional dimension, such as the dimension described as "meaning" of a symptom. That is, what meaning the patient gives to the symptom. ${ }^{37}$ The meaning dimension could be affected by previous experience of the symptom. ${ }^{37}$ Another possible dimension could be the persistence of a symptom, which was used in this thesis. The persistence of an unpleasant symptom can have affect the patient in a negative way. The dimensions of the symp- 
tom experience depend on the patient's ability to articulate what he or she is experiencing. ${ }^{37}$ It could therefore be problematic to apply to patients with decreased cognition, mental health or if there are cultural differences with the experience of the symptom.

\section{Methodological considerations}

This thesis is based on four studies using quantitative data in order to gain knowledge about thirst experience and factors that are associated with thirst in patients with HF. In quantitative studies generalizability is an important criterion to assess the extent to which findings can be applied to other groups and settings. For the studies in this thesis, several points must therefore be highlighted. The small sample sizes in three studies limit the chances to detect differences between groups. Sufficient number of patients in a study is needed to achieve statistical conclusion validity. ${ }^{102}$ Larger sample is more representative for the population. The small samples in this thesis might therefore be less representative for the population of patients with HF. Small samples increases also the risk for type II error, meaning that the researcher concludes that no relationship exists when in fact there is a relationship. ${ }^{113}$

Patients who are enrolled to hospital departments or outpatient clinics represents the accessible population, and therefore a consecutive sampling is often a good choice. ${ }^{102}$ Consecutive sampling refers to a sampling process were all of the patients from an accessible population who meet inclusion criteria for a specified sample size or time interval. Potential sampling bias could deal with seasonal or other time related aspects. Patients have described that thirst gets worse in summer time when it is warm. This bias could be reduced if the time period is long enough to include several seasons. In this thesis patients were included at all seasons to get a variation of the seasonal aspects of thirst. Time of the day might also affect the thirst experience. Patients could not be assessed for thirst at evenings or nights, only in the morning and during the day. 
The findings are limited to patients at hospitals, outpatient clinics and home settings. Comparisons between the settings revealed interesting differences in thirst that could be seen as a strength in this thesis. In one of the studies in this thesis (II) data were collected from many hospitals, which strengthen the generalizability of the findings. The purpose of the exclusion of patients with different conditions/illnesses was to minimize known confounding factors for thirst. For this reason, the findings can not be generalized for these patients with HF.

The recruitment of patients for the studies, as well as data collection, were challenging due to the frailty of HF patients, especially when they were admitted to hospital with decompensated HF. Patients who had severe illness could not be included, or were lost to follow-up. Moreover, for two of the studies, many patients could not be included due to difficulties to understand and speak the Swedish language. This has also consequences for the generalizability of the findings.

The patients admitted to hospital with worsening of HF symptoms were older than the average HF population, and limit therefore the generalising of these findings to younger patients with HF. The knowledge obtained about thirst in the older patients with HF is valuable because many patients with HF are older, and the population of older patients is increasing. Another limitation in this thesis is that men were overrepresented in the studies at the outpatient clinics. Some patients in the studies in this thesis needed help to read the questions in the questionnaires, due to impaired vision. During these situations, investigators must be aware of interviewer bias. An ideal interviewer is neutral, but is difficult to achieve. Respondents and interviewers interact as humans, and this interaction could affect responses. ${ }^{102}$

In order to measure thirst distress, the thirst distress scale for patients with renal failure ${ }^{26}$ was translated and adapted for use in patients with $\mathrm{HF} .{ }^{104}$ The scale has good internal consistency and has been translated for patients with HF in the Netherlands and Japan. ${ }^{96}$ Instruments reliability is the consistency with which it measures the target attribute, and validity is the degree to which an instrument measures what it is supposed to measure. ${ }^{102}$ The limitation of this scale is that it has only been used in research in a few studies. Only the VAS and thirst distress 
scale for patients with renal failure were available to measure thirst when planning for this thesis. ${ }^{38,39,84,86,87,95}$ A VAS has been used to measure pain, quality of life and thirst in healthy persons as well as patients with illness. ${ }^{126-128} 31,41100$, ${ }^{129}$ Other studies have used a numerical rating scale, and lickert scales, which are different to a VAS. ${ }^{100,}{ }^{129}$ This makes comparisons with thirst intensity between different studies troublesome.

Three different questionnaires were used to measure "depressive" characteristics, and could limit the possibility to compare the results. The two-item questionnaire about feeling depressed and feeling anxious were developed by the research team to measure the level of depressive and anxious feeling. These questions were of interest to include in the studies, as the patients with HF with higher level of anxiety or depressive feeling measured with the EQ-5D in the first study had higher thirst intensity compared to HF patients with no or low anxiety or depressive feelings. The strength of this questionnaire is that it is very short and easy for the patient to complete. The items include only the questions of interest, namely the patients feeling of being depressed and feeling anxious. There is a limitation as the scale has not been properly validated, and not used in other studies.

\section{Clinical implications}

The findings from this thesis show that thirst can be increased and distressing over time in patients with HF. Fluid restriction in patients with HF was found to have a significant association with increased thirst.

The findings implicate the importance to identify patients with thirst in order to prevent thirst to become distressing and more troublesome over time, and to find those patients who have highly distressing thirst who need relief. In order to prevent and relieve thirst, nurses should focus on exploring the patients' experience of thirst. By asking the patients if they have thirst as a question in addition to other HF symptoms, nurses could take the first step to find out. Thirst intensity 
on a VAS and thirst distress with the Thirst Distress Scale for Heart failure patients could be used in case patients report having thirst. Nurses should also discuss with the patients how they feel when they are thirsty and if their thirst causes trouble in their daily lives. As patients with HF also can have dry mouths, nurses should ask about mouth dryness. Patients may need help to relieve their thirst and dry mouths.

Patients who have thirst should be evaluated for having a fluid restriction. If a patient has a fluid restriction, nurses should consult a cardiologist to discuss the relevance of a fluid restriction. Each patient with thirst should also be evaluated for the presence of dehydration and depression, in order to try the best possible interventions. Patients who have thirst should be monitored by measuring thirst intensity and thirst distress over time, and interventions to relieve thirst should be evaluated. Nurses should inform patients about thirst, and collaborate with the patients to develop appropriate individual interventions. Nurses should also collaborate with other professionals to be able to offer the best interventions for the patients to relieve their thirst.

\section{Future research}

This thesis has generated new questions for future research and ideas for an intervention about how to prevent and relieve thirst in patients with HF.

- Develop and test interventions that prevent and relieve thirst in patients with HF.

- Develop and evaluate a thirst assessment scale for patients with HF including all dimensions of thirst.

- Evaluate thirst in patients in home-care with severe HF.

- Evaluate thirst in patients with HF with diabetes, oxygen treatment and renal failure.

- Describe the lived experience of thirst in patients with HF.

- Explore the relationship with thirst and HF severity.

- Explore the relation with thirst and depressive symptoms in patients with HF.

- Explore the relationship between thirst and physical-, cognitive-, and social performance in patients with HF. 


\section{CONCLUSIONS}

This thesis has described the complexity of the thirst experience and the influence of factors on the thirst experience in patients with HF. The Theory of Unpleasant Symptoms guided the choice of variables for the thesis and helped to distinguish between the dimensions of thirst experience and the factors influencing thirst. The following conclusions were made based on the findings:

One in five patients with stable HF experienced thirst and $63 \%$ of decompensated HF patients had moderate to severe thirst distress at hospital admission. The highest thirst intensity levels were found in hospitalized patients with HF. Many of the patients with increased thirst also had a dry mouth. Thirst could be experienced as troublesome, and for some patients, this feeling was present every day. In order to prevent thirst and get a valid description of the thirst experience, nurses should ask patients with HF about the frequency of thirst, and measure the thirst intensity and thirst distress, as well as to ask what their thirst feels like and how it is bothering them.

Patients who were thirsty at the first follow-up were more often thirsty also at subsequent follow-ups, and patients with high thirst distress at hospital admission continued to have high thirst distress over time. The risk of becoming thirsty again points out the importance of routine assessment of thirst and to identify patients with recently developed thirst and those who have distressing thirst.

Having a fluid restriction was significantly associated with high thirst intensity, independent of HF severity and HF pharmacological treatment. Having a fluid restriction was also associated with high thirst distress over time.

High plasma urea was associated with persistent thirst and with high thirst intensity and may reflect a higher neurohormonal activation and dehydration in those HF patients with increased thirst. These findings should be confirmed and examined more thoroughly in future studies. 


\section{SVENSK SAMMANFATTNING}

Vårdpersonal såsom sjuksköterskor och läkare möter patienter med hjärtsvikt som berättar att de har ökad och besvärande törst. Törst har beskrivits av patienter med hjärtsvikt som ett bekymmer i deras vardag och som en besvärande upplevelse. För närvarande finns det inga standardiserade förfaranden för att identifiera patienter med ökad törst, eller att hjälpa patienterna att hantera besvärande törst. Forskningen inom området har ökat de senaste tio åren, men fortfarande finns det många obesvarade frågor kring törst hos patienter med hjärtsvikt. Vi vet inte hur många patienter med hjärtsvikt som upplever törst, eller hur många som har en hög grad av besvärande törst. Vi vet heller inte hur patienterna beskriver sin törst eller om den förändras over tiden. Vilka faktorer som påverkar törstupplevelsen är också viktiga att ta reda på för att kunna planera en god vård där insatserna om möjligt kan förhindra uppkomsten av törst och lindra besvärande törst. För att få svar på dessa frågor behövs mer kunskap om hur törst upplevs och vilka faktorer som kan påverka törstupplevelsen.

Det övergripande syftet med denna avhandling var att beskriva törstupplevelsen hos patienter med hjärtsvikt och att beskriva sambandet av törst med fysiologiska, psykologiska och situationsbundna faktorer. Målet var att bidra till att förbättra vården genom att identifiera behov och möjliga strategier för att förebygga och lindra törst hos patienter med hjärtsvikt.

Avhandlingen är baserad på fyra delarbeten med kvantitativa metoder. Första studien är en tvärsnittsstudie (I) och de tre följande studierna är prospektiva studier (II-IV). Patienterna rekryterades på sjukhus i samband med en försämring av hjärtsviktstillståndet (I, II, IV) eller vid ett besök på en hjärtsviktsmottagning (III). Patienterna följdes över tid med mätning av törst frekvens/förändringar av törst, törst intensitet, grad av törstbesvär, och törst kvalitet. Fysiologiska (intorkning, hjärtsviktsspecifika markörer, kön, ålder), psykologiska (depressiva symtom, stress) och situationsbundna faktor variabler (förekomst av 
vätskerestriktion, egenvårdsbeteende, tid på dygnet) studerades i förhållande till törstupplevelsen. Förekomst av törst upplevdes av $20 \%$ av patienterna (II) och $63 \%$ av patienterna med försämring av sin hjärtsvikt upplevde måttliga till svåra törstbesvär (IV). Patienter på en hjärtsviktsmottagning som rapporterade törst vid det första besöket var oftare törstiga även vid uppföljningsbesöken på mottagningen jämfört med hjärtsviktspatienter som inte rapporterade törst vid första besöket (II). Törst intensiteten var betydligt högre hos patienter med en hjärtsviktsförsämring jämfört med patienter utan hjärtsvikt (median 75 vs. $25 \mathrm{~mm}$, visuell analog skala [VAS] 0-100 mm, P <0,001) (I). Under en upptitreringsperiod med läkemedel för hjärtsvikt, ökade törst intensiteten hos $67 \%$ av patienterna. Patienter som hade hög grad av törstbesvär vid ankomsten till sjukhuset för en försämring av hjärtsvikt, fortsatte att ha högre grad av törstbesvär i jämförelse med patienter som hade lägre grad av törstbesvär vid sjukhusankomsten (IV). Ett stort antal patienter besvärades av muntorrhet när de var törstiga (III, IV). Patienter med vätskerestriktion hade en högre grad av törstbesvär över tid i jämförelse med de som inte hade vätskerestriktion. De patienter som kände sig deprimerade hade högre törstintensitet över tid i jämförelse med de som inte kände sig deprimerade (IV). Törst var associerat med vätskerestriktion (III-IV), en högre koncentration av serum urea (II-III), och depressiva symptom (II).

Många patienter med hjärtsvikt upplever törstintensitet och törstbesvär. Patienter som rapporterade törst vid första mottagningsbesöket hade oftare törst vid efterföljande mottagningsbesök. De viktigaste faktorerna för törstintensitet eller törstbesvär var vätskerestriktion, en högre koncentration av plasma urea, och depressiva symtom. Sjuksköterskor bör fråga patienter med hjärtsvikt om de är törstiga och mäta deras törstintensitet och grad av törstbesvär, samt att fråga dem om törst besvärar dem. Varje patient bör utvärderas för om en vätskerestriktion verkligen behövs, om patienten är uttorkad och behöver dricka mer eller måste behandlas för depression. 


\section{ACKNOWLEDGEMENTS}

I want to express my warmest gratitude to all of you who in different ways have supported me and contributed to this thesis. In particular, I wish to thank:

All patients, who participated in the studies. Thank you!

Professor Tiny Jaarsma, my main supervisor. First, thank you for having me as your doctoral student. I searched with "lantern" for a nurse and professor in the field of cardiology in Sweden, and fortunately I found you. I want to thank you for always believing in me and encouraging me. Being there when I needed. You have always and generously shared your knowledge and inspired me to continue working as a researcher.

Professor Robert Hahn, my co-supervisor for your scientific guidance and valuable advice during the years. You provided important input to my work. You always encouraged to work hard and to bring clarity into research results.

Martje van der Wal. Although you never had the official title, I always valued you as my co-supervisor. I thank you for all the support, engagement and encouragement through the years. We wrote three articles together and you always shared your valuable knowledge as a researcher and as a heart failure nurse. I look forward to work with you in new projects.

Fredrik Sjöstrand, my co-author. I want to thank you for arousing my interest in research many years ago when we started with your studies. Thanks to you, some years later, I was able to start my first study and this was the beginning to my thesis. I also thank you for being like a mentor during times when I needed guidance as a doctoral student.

Misook Chung, professor and co-author. Thank you for sharing your knowledge and for encouraging me to learn a new way for me to analyse data.

Patrik Lyngå and Ewa Hägglund, heart failure nurses and co-authors. Thank you for the work with collecting data to the study and to your scientific contribu- 
tion in the article. Thank you also for sharing your valuable knowledge about patients with heart failure. Hopefully we will get an opportunity to work with a new project together again in near future.

Pia Jonsson, collegue at Södertälje hospital and friend. I want to thank you for the excellent work with collecting data in one of my studies. I also want to thank you for being there as a friend, believing in me and always encouraged me in my work with this thesis.

All doctoral collegues at the Department of Social and Welfare Studies and the Department of Medical and Health Sciences, a big thank you for your support through the years and for valuable discussions at our seminars, doctoral courses and congresses all over the world. Special thanks to Ghassan Mourad for always being helpful and supportive and to Jeanette Eckerblad and Christina Andreae for your friendship and valuable discussions about symptoms. To Lisa Hjelmfors for your friendship and for being a good listener. Thanks also to Leonie Klompstra, Brynja Ingadottir, Lena Näsström, Helena Kilander, Carina Hjelm, Maria Liljeroos and Jenny Drott for nice discussions and support. I also want to thank Naoko Kato, co-worker and post-doc., for sharing your knowledge and being supportive. I look forward to work together with you with our "thirsty-studies".

The management and staff at the Departments of Internal Medicine and Geriatrics, Södertälje sjukhus, who kindly gave me access to the hospital units and showing interest in my projects.

Senior researchers at the Department of Social and Welfare Studies and the Department of Medical and Health Sciences for reading and giving feed-back on my manuscripts. Special thanks to Professor Jan Mårtensson, Professor Anna Strömberg, Anita Kärner Köhler, Peter Johansson and Associate professor Kristofer Årestedt for encouraging me in my work in different ways.

Professor Simon Thornton for sharing your knowledge about the physiology of body fluid system and thirst, for taking interest in my research and for your valuable questions about thirst in patients with heart failure.

Niclas Silfverhammar, for all administrative help and always being available to answer questions and to give help when needed. 
Elisabeth Wilhelm for valuable advice on statistics.

Sofia McGarvey for valuable help with language revision in now published articles.

To my mother Tuula Lempiäinen and my sister Nina Waldréus with family for being there and waiting patiently during these years, and for your help with practical issues at home when needed.

The most important persons in my life, my beloved family Michael, Adam and Alex Hagelin- with you being there I managed to finish my thesis. I promise, now I will no more ask you how thirsty you are, grading on a line from 0 to 100 . I thank you from the bottom of my heart for the support, patience and love.

The studies in this thesis were financially supported by:

-HjärtLungsjukas Riksförbund; -Hjärt-Lung Fonden; -Lindhés advokatbyrå;

-Mats Klebergs Stiftelse; -Stockholms läns landsting (Pick-Up project);

-Svensksjuksköterskeförening, Estrid Rodhe; -SvenskaSmärtaFonden; and

-Södertälje Sjukhus AB. 


\section{REFERENCES}

1. Toto KH. Regulation of plasma osmolality: thirst and vasopressin. Crit Care Nurs Clin North Am. Dec 1994;6(4):661-674.

2. Porth CM, Erickson M. Physiology of thirst and drinking: implication for nursing practice. Heart Lung. May 1992;21(3):273-282.

3. Guyton AC, Hall JE. Textbook of Medical Physiology. 12 ed. Philadelphia: Saunders, Elsevier; 2011.

4. Nordgren L, Sorensen S. Symptoms experienced in the last six months of life in patients with end-stage heart failure. Eur $J$ Cardiovasc Nurs. Sep 2003;2(3):213-217.

5. Holmes JH, Montgomery A. Thirst as a symptom. American Journal of the Medical Sciences. 1953;225(3):281-286.

6. Brannstrom M, Ekman I, Norberg A, Boman K, Strandberg G. Living with severe chronic heart failure in palliative advanced home care. Eur $J$ Cardiovasc Nurs. Dec 2006;5(4):295-302.

7. Falk S, Wahn AK, Lidell E. Keeping the maintenance of daily life in spite of chronic heart failure. A qualitative study. Eur J Cardiovasc Nurs. Sep 2007;6(3):192-199.

8. Reilly CM, Higgins M, Smith A, Culler SD, Dunbar SB. Isolating the benefits of fluid restriction in patients with heart failure: A pilot study. Eur J Cardiovasc Nurs. Dec 2015;14(6):495-505.

9. Reilly CM, Meadows K, Dunbar S. Thirst and QOL in persons with heart failure. Heart Lung. 2010;4:1.

10. van der Wal MH, Jaarsma T, Moser DK, van Gilst WH, van Veldhuisen DJ. Qualitative examination of compliance in heart failure patients in The Netherlands. Heart Lung. Mar-Apr 2010;39(2):121-130.

11. Waldreus N, Hahn RG, Jaarsma T. Thirst in heart failure: a systematic literature review. Eur J Heart Fail. Feb 2013;15(2):141-149.

12. McMurray JJ, Adamopoulos S, Anker SD, et al. ESC guidelines for the diagnosis and treatment of acute and chronic heart failure 2012: The Task Force for the Diagnosis and Treatment of Acute and Chronic Heart Failure 2012 of the European Society of Cardiology. Developed in collaboration with the Heart Failure Association (HFA) of the ESC. Eur J Heart Fail. Aug 2012;14(8):803-869.

13. Desai AS, Stevenson LW. Rehospitalization for heart failure: predict or prevent? Circulation. Jul 24 2012;126(4):501-506.

14. Jonsson A, Edner M, Alehagen U, Dahlstrom U. Heart failure registry: a valuable tool for improving the management of patients with heart failure. Eur J Heart Fail. Jan 2010;12(1):25-31.

15. The ICN code of ethics for nurses. 2012. http://www.icn.ch/. Accessed 22 February, 2016. 
16. Brannstrom M, Boman K. Effects of person-centred and integrated chronic heart failure and palliative home care. PREFER: a randomized controlled study. Eur J Heart Fail. Oct 2014;16(10):1142-1151.

17. Fors A, Taft C, Ulin K, Ekman I. Person-centred care improves self-efficacy to control symptoms after acute coronary syndrome: a randomized controlled trial. Eur J Cardiovasc Nurs. Dec 232015.

18. Riegel B, Jaarsma T, Stromberg A. A middle-range theory of self-care of chronic illness. ANS Adv Nurs Sci. Jul-Sep 2012;35(3):194-204.

19. Morgan S, Yoder LH. A concept analysis of person-centered care. J Holist Nurs. Mar 2012;30(1):6-15.

20. Allida SM, Inglis SC, Davidson PM, Lal S, Hayward CS, Newton PJ. Thirst in chronic heart failure: a review. J Clin Nurs. Apr 2015;24(7-8):916-926.

21. Johansson P, Lesman-Leegte I, Lundgren J, et al. Time-course of depressive symptoms in patients with heart failure. $J$ Psychosom Res. Mar 2013;74(3):238-243.

22. Hoekstra T, Jaarsma T, Sanderman R, van Veldhuisen DJ, Lesman-Leegte I. Perceived sexual difficulties and associated factors in patients with heart failure. Am Heart J. Feb 2012;163(2):246-251.

23. Smith OR, Kupper N, de Jonge P, Denollet J. Distinct trajectories of fatigue in chronic heart failure and their association with prognosis. Eur J Heart Fail. Aug 2010;12(8):841-848.

24. Campbell M, Fitzpatrick R, Haines A, et al. Framework for design and evaluation of complex interventions to improve health. BMJ. Sep 16 2000;321(7262):694-696.

25. Greenleaf JE. Problem: thirst, drinking behavior, and involuntary dehydration. Med Sci Sports Exerc. Jun 1992;24(6):645-656.

26. Welch JL. Development of the thirst distress scale. Nephrol Nurs J. Aug 2002;29(4):337-341; discussion 343.

27. Armstrong LE, Johnson EC, McKenzie AL, Ellis LA, Williamson KH. Endurance Cyclist Fluid Intake, Hydration Status, Thirst and Thermal Sensations: Gender Differences. Int J Sport Nutr Exerc Metab. Oct 19 2015.

28. Yamamoto T, Shimizu M, Morioka M, Kitano M, Wakabayashi H, Aizawa $\mathrm{N}$. Role of angiotensin II in the pathogenesis of hyperdipsia in chronic renal failure. JAMA. Aug 1 1986;256(5):604-608.

29. Bots CP, Brand HS, Veerman EC, et al. Chewing gum and a saliva substitute alleviate thirst and xerostomia in patients on haemodialysis. Nephrol Dial Transplant. Mar 2005;20(3):578-584.

30. Bots CP, Brand HS, Veerman EC, et al. The management of xerostomia in patients on haemodialysis: comparison of artificial saliva and chewing gum. Palliat Med. Apr 2005;19(3):202-207.

31. Morita T, Tei Y, Tsunoda J, Inoue S, Chihara S. Determinants of the sensation of thirst in terminally ill cancer patients. Support Care Cancer. May 2001;9(3):177-186.

32. Musgrave CF, Bartal N, Opstad J. The sensation of thirst in dying patients receiving i.v. hydration. J Palliat Care. Winter 1995;11(4):17-21. 
33. Thompson CJ, Baylis PH. Thirst in diabetes insipidus: clinical relevance of quantitative assessment. $Q J$ Med. Oct 1987;65(246):853-862.

34. Kamoi K, Ishibashi M, Yamaji T. Thirst and plasma levels of vasopressin, angiotensin II and atrial natriuretic peptide in patients with non-insulindependent diabetes mellitus. Diabetes Res Clin Pract. Mar 1991;11(3):195-202.

35. Stotts NA, Arai SR, Cooper BA, Nelson JE, Puntillo KA. Predictors of thirst in intensive care unit patients. $J$ Pain Symptom Manage. Mar 2015;49(3):530-538.

36. Landstrom M, Rehn IM, Frisman GH. Perceptions of registered and enrolled nurses on thirst in mechanically ventilated adult patients in intensive care units-a phenomenographic study. Intensive Crit Care Nurs. Jun 2009;25(3):133-139.

37. Lenz ER, Pugh LC. The Theory of Unpleasant Symptoms. In: Smith MJ, Liehr PR, eds. Middle range theory for nursing. 3rd ed. New York, US: Springer Publishing Company; 2014: 165-195.

38. Albert NM, Nutter B, Forney J, Slifcak E, Tang WH. A randomized controlled pilot study of outcomes of strict allowance of fluid therapy in hyponatremic heart failure (SALT-HF). J Card Fail. Jan 2013;19(1):1-9.

39. Aliti GB, Rabelo ER, Clausell N, Rohde LE, Biolo A, Beck-da-Silva L. Aggressive fluid and sodium restriction in acute decompensated heart failure: a randomized clinical trial. JAMA Intern Med. Jun 24 2013;173(12):1058-1064.

40. Allida SM, Inglis SC, Davidson PM, Hayward CS, Newton PJ. Measurement of thirst in chronic heart failure - A review. Contemp Nurse. 2014;48(1):29.

41. Wirth JB, Folstein MF. Thirst and weight gain during maintenance hemodialysis. Psychosomatics. Nov 1982;23(11):1125-1127, 1130-1121, 1134.

42. Konstam MA, Gheorghiade M, Burnett JC, Jr., et al. Effects of oral tolvaptan in patients hospitalized for worsening heart failure: the EVEREST Outcome Trial. JAMA. Mar 28 2007;297(12):1319-1331.

43. Lenz ER, Pugh LC, Milligan RA, Gift A, Suppe F. The middle-range theory of unpleasant symptoms: an update. ANS Adv Nurs Sci. Mar 1997;19(3):14-27.

44. Edwards E. Symptoms. The Lancet. 2008;371:1157.

45. Ekman I, Cleland JG, Andersson B, Swedberg K. Exploring symptoms in chronic heart failure. Eur J Heart Fail. Aug 2005;7(5):699-703.

46. Brink E, Skott C. Caring about symptoms in person-centred care. Open Journal of Nursing. 2013;3:563-567.

47. Thornton SN. Thirst and hydration: physiology and consequences of dysfunction. Physiol Behav. Apr 26 2010;100(1):15-21.

48. Mattes RD. Hunger and thirst: issues in measurement and prediction of eating and drinking. Physiol Behav. Apr 26 2010;100(1):22-32. 
49. McKiernan F, Houchins JA, Mattes RD. Relationships between human thirst, hunger, drinking, and feeding. Physiol Behav. Aug 6 2008;94(5):700-708.

50. Gross CR, Lindquist RD, Woolley AC, Granieri R, Allard K, Webster B. Clinical indicators of dehydration severity in elderly patients. $J$ Emerg Med. May-Jun 1992;10(3):267-274.

51. Gupta A, Epstein JB, Sroussi H. Hyposalivation in elderly patients. J Can Dent Assoc. Nov 2006;72(9):841-846.

52. Ship JA, Fischer DJ. The relationship between dehydration and parotid salivary gland function in young and older healthy adults. $J$ Gerontol A Biol Sci Med Sci. Sep 1997;52(5):M310-319.

53. Eccles R. Role of cold receptors and menthol in thirst, the drive to breathe and arousal. Appetite. Feb 2000;34(1):29-35.

54. Eccles R, Du-Plessis L, Dommels Y, Wilkinson JE. Cold pleasure. Why we like ice drinks, ice-lollies and ice cream. Appetite. 2013;71:357-360.

55. Fitzsimons JT. Angiotensin, thirst, and sodium appetite. Physiol Rev. Jul 1998;78(3):583-686.

56. Arai SR, Butzlaff A, Stotts NA, Puntillo KA. Quench the thirst: lessons from clinical thirst trials. Biol Res Nurs. Oct 2014;16(4):456-466.

57. Stachenfeld NS, DiPietro L, Nadel ER, Mack GW. Mechanism of attenuated thirst in aging: role of central volume receptors. Am J Physiol. Jan 1997;272(1 Pt 2):R148-157.

58. Rolls BJ, Phillips PA. Aging and disturbances of thirst and fluid balance. Nutr Rev. Mar 1990;48(3):137-144.

59. Farrell MJ, Zamarripa F, Shade R, et al. Effect of aging on regional cerebral blood flow responses associated with osmotic thirst and its satiation by water drinking: a PET study. Proc Natl Acad Sci U S A. Jan 8 2008;105(1):382-387.

60. Kazory A. Emergence of blood urea nitrogen as a biomarker of neurohormonal activation in heart failure. Am J Cardiol. 2010;106:694700 .

61. Gotsman I, Zwas D, Planer D, Admon D, Lotan C, Keren A. The significance of serum urea and renal function in patients with heart failure. Medicine (Baltimore). Jul 2010;89(4):197-203.

62. Cauthen CA, Lipinski MJ, Abbate A, et al. Relation of blood urea nitrogen to long-term mortality in patients with heart failure. Am J Cardiol. Jun 1 2008;101(11):1643-1647.

63. Stachenfeld NS. Acute effects of sodium ingestion on thirst and cardiovascular function. Curr Sports Med Rep. Jul-Aug 2008;7(4 Suppl):S7-13.

64. Bolhuis DP, Lakemond CM, de Wijk RA, Luning PA, de Graaf C. Effect of salt intensity in soup on ad libitum intake and on subsequent food choice. Appetite. Feb 2012;58(1):48-55.

65. Seckl JR, Williams TD, Lightman SL. Oral hypertonic saline causes transient fall of vasopressin in humans. Am J Physiol. Aug 1986;251(2 Pt 2):R214-217. 
66. Thomson WM. Dry mouth and older people. Aust Dent J. Mar 2015;60 Suppl 1:54-63.

67. AHA. The Criteria Committee of the New York Heart Association. 9th ed. Boston: Mass: Little, Brown \& Co; 1994.

68. Ambrosy AP, Fonarow GC, Butler J, et al. The global health and economic burden of hospitalizations for heart failure: lessons learned from hospitalized heart failure registries. $J$ Am Coll Cardiol. Apr 1 2014;63(12):1123-1133.

69. Zarrinkoub R, Wettermark B, Wandell P, et al. The epidemiology of heart failure, based on data for 2.1 million inhabitants in Sweden. Eur J Heart Fail. Sep 2013;15(9):995-1002.

70. Dunlay SM, Roger VL. Understanding the epidemic of heart failure: past, present, and future. Curr Heart Fail Rep. Dec 2014;11(4):404-415.

71. Zambroski $\mathrm{CH}$, Moser DK, Bhat G, Ziegler C. Impact of symptom prevalence and symptom burden on quality of life in patients with heart failure. Eur J Cardiovasc Nurs. Sep 2005;4(3):198-206.

72. Hare DL, Toukhsati SR, Johansson P, Jaarsma T. Depression and cardiovascular disease: a clinical review. Eur Heart J. Jun 1 2014;35(21):1365-1372.

73. Bekelman DB, Havranek EP, Becker DM, et al. Symptoms, depression, and quality of life in patients with heart failure. $J$ Card Fail. Oct 2007;13(8):643-648.

74. Blinderman CD, Homel P, Billings JA, Portenoy RK, Tennstedt SL. Symptom distress and quality of life in patients with advanced congestive heart failure. J Pain Symptom Manage. Jun 2008;35(6):594-603.

75. Rutledge T, Reis VA, Linke SE, Greenberg BH, Mills PJ. Depression in heart failure a meta-analytic review of prevalence, intervention effects, and associations with clinical outcomes. $J$ Am Coll Cardiol. Oct 17 2006;48(8):1527-1537.

76. Lainscak M, Blue L, Clark AL, et al. Self-care management of heart failure: practical recommendations from the Patient Care Committee of the Heart Failure Association of the European Society of Cardiology. Eur J Heart Fail. Feb 2011;13(2):115-126.

77. Falk H, Ekman I, Anderson R, Fu M, Granger B. Older patients' experiences of heart failure-an integrative literature review. J Nurs Scholarsh. Sep 2013;45(3):247-255.

78. Juenger J, Schellberg D, Kraemer S, et al. Health related quality of life in patients with congestive heart failure: comparison with other chronic diseases and relation to functional variables. Heart. Mar 2002;87(3):235241.

79. Jeon YH, Kraus SG, Jowsey T, Glasgow NJ. The experience of living with chronic heart failure: a narrative review of qualitative studies. $B M C$ Health Serv Res. 2010;10:77.

80. Packer M, McMurray JJ, Desai AS, et al. Angiotensin receptor neprilysin inhibition compared with enalapril on the risk of clinical progression in 
surviving patients with heart failure. Circulation. Jan 6 2015;131(1):5461.

81. Warriner DR, Sheridan PJ. End-stage heart failure non-pharmacological therapy: recent advances in pacemakers, pressure monitors, pumps and other devices. Postgrad Med J. Mar 2014;90(1061):164-170.

82. Jonkman NH, Westland H, Groenwold RH, et al. Do Self-Management Interventions Work in Patients With Heart Failure? An Individual Patient Data Meta-Analysis. Circulation. Feb 122016.

83. Reeder KM, Ercole PM, Peek GM, Smith CE. Symptom perceptions and self-care behaviors in patients who self-manage heart failure. $J$ Cardiovasc Nurs. Jan-Feb 2015;30(1):E1-7.

84. Holst M, Stromberg A, Lindholm M, Willenheimer R. Description of selfreported fluid intake and its effects on body weight, symptoms, quality of life and physical capacity in patients with stable chronic heart failure. $J$ Clin Nurs. Sep 2008;17(17):2318-2326.

85. Holst M, Stromberg A, Lindholm M, Willenheimer R. Liberal versus restricted fluid prescription in stabilised patients with chronic heart failure: result of a randomised cross-over study of the effects on healthrelated quality of life, physical capacity, thirst and morbidity. Scand Cardiovasc J. Oct 2008;42(5):316-322.

86. Philipson H, Ekman I, Forslund HB, Swedberg K, Schaufelberger M. Salt and fluid restriction is effective in patients with chronic heart failure. Eur $J$ Heart Fail. Nov 2013;15(11):1304-1310.

87. Philipson H, Ekman I, Swedberg K, Schaufelberger M. A pilot study of salt and water restriction in patients with chronic heart failure. Scand Cardiovasc J. Aug 2010;44(4):209-214.

88. Crane PB. Fatigue and physical activity in older women after myocardial infarction. Heart Lung. Jan-Feb 2005;34(1):30-38.

89. Oh EG, Kim CJ, Lee WH, Kim SS. Correlates of fatigue in Koreans with chronic lung disease. Heart Lung. Jan-Feb 2004;33(1):13-20.

90. Parshall MB, Welsh JD, Brockopp DY, Heiser RM, Schooler MP, Cassidy KB. Dyspnea duration, distress, and intensity in emergency department visits for heart failure. Heart Lung. Jan-Feb 2001;30(1):47-56.

91. Brant JM, Beck S, Miaskowski C. Building dynamic models and theories to advance the science of symptom management research. J Adv Nurs. Jan 2010;66(1):228-240.

92. Lenz ER, Suppe F, Gift AG, Pugh LC, Milligan RA. Collaborative development of middle-range nursing theories: toward a theory of unpleasant symptoms. ANS Adv Nurs Sci. Mar 1995;17(3):1-13.

93. Jaarsma T, Van Der Wal MH, Hogenhuis J, et al. Design and methodology of the $\mathrm{COACH}$ study: a multicenter randomised Coordinating study evaluating Outcomes of Advising and Counselling in Heart failure. Eur $J$ Heart Fail. Mar 1 2004;6(2):227-233.

94. Arai S, Stotts N, Puntillo K. Thirst in critically ill patients: from physiology to sensation. Am J Crit Care. Jul 2013;22(4):328-335. 
95. Holst M, Stromberg A, Lindholm M, Uden G, Willenheimer R. Fluid restriction in heart failure patients: is it useful? The design of a prospective, randomised study. Eur $J$ Cardiovasc Nurs. Sep 2003;2(3):237-242.

96. Waldréus N, Jaarsma T. Evaluation of a nine-item thirst distress scale for patients with heart failure. Eur J Cardiovasc Nurs. 2015;14:S70.

97. EuroQol Group. User guide. 2007 http://www.euroqol.org/. Accessed 3 February, 2009.

98. Radloff L. A self-report depression scale for research in the general population. Appl Psychol Meas. 1977;1:385-401.

99. Jaarsma T, Arestedt KF, Martensson J, Dracup K, Stromberg A. The European Heart Failure Self-care Behaviour scale revised into a nine-item scale (EHFScB-9): a reliable and valid international instrument. Eur $J$ Heart Fail. Jan 2009;11(1):99-105.

100. Flaherty SA. Pain measurement tools for clinical practice and research. AANA J. Apr 1996;64(2):133-140.

101. Brislin RW. Back-translation for cross-cultural research. Journal of Crosscultural psychology. 1970;1:185-216.

102. Polit DF, Beck CT. Nursing Research: Generating and Assessing Evidence for Nursing Practice 9th ed. Philadelphia: Wolters Kluwer Health/Lippincott Williams \& Wilkins; 2012.

103. Jones PS, Lee JW, Philips LR, Zhang XE, Jaceldo KB. An adaption of Brislin's translation model for cross-cultural research. Nursing Research 2001;50:300-304.

104. Waldréus N, Hahn R, Jaarsma T. Suitability of the Thirst distress scale for heart failure patients. Eur J Heart Fail Suppl. 2012;11:S49-S50.

105. Vellone E, Jaarsma T, Stromberg A, et al. The European Heart Failure Self-care Behaviour Scale: new insights into factorial structure, reliability, precision and scoring procedure. Patient Educ Couns. Jan 2014;94(1):97102.

106. Armstrong LE, Soto JA, Hacker FT, Jr., Casa DJ, Kavouras SA, Maresh CM. Urinary indices during dehydration, exercise, and rehydration. Int $J$ Sport Nutr. Dec 1998;8(4):345-355.

107. Casa DJ, Armstrong LE, Hillman SK, et al. National athletic trainers' association position statement: fluid replacement for athletes. J Athl Train. Apr 2000;35(2):212-224.

108. Bennett JA, Riegel B, Bittner V, Nichols J. Validity and reliability of the NYHA classes for measuring research outcomes in patients with cardiac disease. Heart Lung. Jul-Aug 2002;31(4):262-270.

109. Brooks RG, Jendteg S, Lindgren B, Persson U, Bjork S. EuroQol: healthrelated quality of life measurement. Results of the Swedish questionnaire exercise. Health Policy. Jun 1991;18(1):37-48.

110. Brooks R. EuroQol: the current state of play. Health Policy. Jul 1996;37(1):53-72. 
111. Coons SJ, Rao S, Keininger DL, Hays RD. A comparative review of generic quality-of-life instruments. Pharmacoeconomics. Jan 2000;17(1):13-35.

112. Weitzman ED, Fukushima D, Nogeire C, Roffwarg H, Gallagher TF, Hellman L. Twenty-four hour pattern of the episodic secretion of cortisol in normal subjects. J Clin Endocrinol Metab. Jul 1971;33(1):14-22.

113. Field AP. Discovering statistics using IBM SPSS statistics. 4th ed. Vol 4. London: Sage publications; 2013.

114. World Medical A. World Medical Association Declaration of Helsinki: ethical principles for medical research involving human subjects. JAMA. Nov 27 2013;310(20):2191-2194.

115. Smith OR, Denollet J, Schiffer AA, Kupper N, Gidron Y. Patient-rated changes in fatigue over a 12-month period predict poor outcome in chronic heart failure. Eur J Heart Fail. Apr 2009;11(4):400-405.

116. Smith OR, Gidron Y, Kupper N, Winter JB, Denollet J. Vital exhaustion in chronic heart failure: symptom profiles and clinical outcome. $J$ Psychosom Res. Mar 2009;66(3):195-201.

117. Dodd M, Janson S, Facione N, et al. Advancing the science of symptom management. $J$ Adv Nurs. Mar 2001;33(5):668-676.

118. Lam C, Smeltzer SC. Patterns of symptom recognition, interpretation, and response in heart failure patients: an integrative review. $J$ Cardiovasc Nurs. Jul-Aug 2013;28(4):348-359.

119. Kugler C, Geyer S, Gottlieb J, Simon A, Haverich A, Dracup K. Symptom experience after solid organ transplantation. J Psychosom Res. Feb 2009;66(2):101-110.

120. Yancy CW, Jessup M, Bozkurt B, et al. 2013 ACCF/AHA guideline for the management of heart failure: a report of the American College of Cardiology Foundation/American Heart Association Task Force on Practice Guidelines. J Am Coll Cardiol. Oct 15 2013;62(16):e147-239.

121. Filippatos G, Rossi J, Lloyd-Jones DM, et al. Prognostic value of blood urea nitrogen in patients hospitalized with worsening heart failure: insights from the Acute and Chronic Therapeutic Impact of a Vasopressin Antagonist in Chronic Heart Failure (ACTIV in CHF) study. J Card Fail. Jun 2007;13(5):360-364.

122. Testani JM, Cappola TP, Brensinger CM, Shannon RP, Kimmel SE. Interaction between loop diuretic-associated mortality and blood urea nitrogen concentration in chronic heart failure. $\mathrm{J} \mathrm{Am} \mathrm{Coll} \mathrm{Cardiol.} \mathrm{Jul} 19$ 2011;58(4):375-382.

123. Katon W, Sullivan M, Walker E. Medical symptoms without identified pathology: relationship to psychiatric disorders, childhood and adult trauma, and personality traits. Ann Intern Med. May 1 2001;134(9 Pt 2):917-925.

124. Morris MC, Rao U, Garber J. Cortisol responses to psychosocial stress predict depression trajectories: social-evaluative threat and prior depressive episodes as moderators. J Affect Disord. Dec 20 2012;143(13):223-230. 
125. McEvoy L, Duffy A. Holistic practice--a concept analysis. Nurse Educ Pract. Nov 2008;8(6):412-419.

126. Dominic SC, Ramachandran S, Somiah S, Mani K, Dominic SS. Quenching the thirst in dialysis patients. Nephron. 1996;73(4):597-600.

127. Figaro MK, Mack GW. Regulation of fluid intake in dehydrated humans: role of oropharyngeal stimulation. Am J Physiol. Jun 1997;272(6 Pt 2):R1740-1746.

128. Phillips PA, Bretherton M, Johnston CI, Gray L. Reduced osmotic thirst in healthy elderly men. Am J Physiol. Jul 1991;261(1 Pt 2):R166-171.

129. Good M, Stiller C, Zauszniewski JA, Anderson GC, Stanton-Hicks M, Grass JA. Sensation and Distress of Pain Scales: reliability, validity, and sensitivity. J Nurs Meas. Winter 2001;9(3):219-238. 



\section{Papers}

The articles associated with this thesis have been removed for copyright reasons. For more details about these see:

http://urn.kb.se/resolve?urn=urn:nbn:se:liu:diva-126151 